\title{
CEsifo WORKING

\section{Spin Doctors: A Model and an Experimental Investigation of Vague Disclosure}

Marvin Deversi, Alessandro Ispano, Peter Schwardmann 


\section{Impressum:}

CESifo Working Papers

ISSN 2364-1428 (electronic version)

Publisher and distributor: Munich Society for the Promotion of Economic Research - CESifo $\mathrm{GmbH}$

The international platform of Ludwigs-Maximilians University's Center for Economic Studies and the ifo Institute

Poschingerstr. 5, 81679 Munich, Germany

Telephone +49 (o)89 2180-2740, Telefax +49 (o)89 2180-17845, email office@cesifo.de

Editors: Clemens Fuest, Oliver Falck, Jasmin Gröschl

www.cesifo-group.org/wp

An electronic version of the paper may be downloaded

- from the SSRN website: $\quad$ www.SSRN.com

- from the RePEc website: $\quad$ www.RePEc.org

- from the CESifo website: www.CESifo-group.org/wp 


\title{
Spin Doctors: A Model and an Experimental Investigation of Vague Disclosure
}

\begin{abstract}
Unfavorable news are often delivered under the disguise of vagueness. But are people sufficiently naive to be fooled by such positive spin? We use a theoretical model and a laboratory experiment to study the strategic use of vagueness in a voluntary disclosure game. Consider a sender who aims at inflating a receiver's estimate of her type and who may disclose any interval that contains her actual type. Theory predicts that when facing a possibly naive receiver, the sender discloses an interval that separates her from worse types but is upwardly vague. Senders in the experiment adopt this strategy and some (naive) receivers are systematically misled by it. Imposing precise disclosure leads to less, but more easily interpretable, disclosure. Both theory and experimental data further suggest that imposing precision improves overall information transmission and is especially beneficial to naive receivers. Our results have implications for the rules that govern the disclosure of qualityrelevant information by firms, the disclosure of research findings by scientists, and testimonies in a court of law.
\end{abstract}

JEL-Codes: D820, D830, C920, L150, D040.

Keywords: communication, naivete, flexibility, regulation.

Marvin Deversi

University of Munich (LMU) / Germany

marvin.deversi@econ.Imu.de
Alessandro Ispano

THEMA-Université de Cergy-Pontoise I

France

alessandro.ispano@gmail.com

Peter Schwardmann

University of Munich (LMU) / Germany

peter.schwardmann@econ.Imu.de

September 2018

We thank Ron Berman, Milo Bianchi, Jeanne Hagenbach, Martin Kocher, David Laibson, George Loewenstein, John List, Michael Luca, Daniel Martin, Klaus Schmidt, Simeon Schudy and seminar audiences at the EEA Congress in Cologne, SITE Experimental Economics, $11^{\text {th }}$ Workshop on the Economics of Advertising and Marketing at Columbia University, RGS Workshop at the University of Essen, SABE/IAREP Conference at Middlesex University, Workshop on Limited Attention at the University of Copenhagen, ESA World Meeting in San Diego, Meeting of the AFSE at PSE, TU Munich, University of Vienna, and University of Amsterdam for helpful comments. We are thankful for support by the German Science Foundation (DFG) through the CRC TR190. Deversi acknowledges funding through the doctoral program "Evidence-Based Economics" and DFG project grant KO 4100/1-1. We thank Carolin Wagner for excellent research assistance. 


\section{Introduction}

In many settings, informed parties not only decide whether to disclose verifiable private information, but also enjoy substantial flexibility in how information is disclosed. One way to exploit flexibility in disclosure is by means of vague messages. Vague messages are designed to inflate a receiver's perception of the sender's type by clearly separating from worse but not from better types. They are not outright lies, which may invite litigation, but merely put a positive spin on unfavorable news. Consider the following examples.

A college that ranks 10th in the latest US news ranking is likely to call itself a top 10 college rather than referring to itself as the 10th ranked college. A wine whose sole designation of origin is France is unlikely to come from the Bordeaux region, renowned for its superior wine. A wine whose sole designation of origin is Bordeaux is unlikely to come from Pomerol, an especially beloved subregion of Bordeaux. Researchers often refer to "significance at the 5 percent level" when a p-value is just below 0.05 , while stating the exact p-value for a highly significant result. During legal proceedings, a defendant may try to convince a jury of her innocence by answering only those questions that are likely to exonerate her.

Sophisticated receivers understand and can correct for senders' strategic use of vagueness. But if these deceptive practices are deployed on naive receivers, then they result in systematic misperceptions. We model voluntary disclosure to receivers of heterogeneous strategic sophistication under both flexible language, which facilitates vague messages, and precise language. We then test the model's assumptions and predictions in the experimental laboratory. In doing so, we seek to answer three main questions. How do senders optimally design messages to exploit receivers' naivete? Are (some) receivers systematically fooled by vague disclosure? And can restricting senders' flexibility in disclosure improve information transmission? 
The Model. Consider a voluntary disclosure game in which a privately informed sender decides whether and how to disclose verifiable information about her type to a receiver. The sender's payoff is increasing in the receiver's belief about the sender's type, while the receiver's payoff is increasing in the accuracy of her belief. We distinguish between two language regimes: in the precise language regime, if the sender discloses, then the message has to reflect her exact type; in the flexible language regime a sender may send vague messages, i.e. a message that is any interval that contains the sender's true type.

If all agents are rational, the unique equilibrium outcome of the precise language regime features full information revelation (Grossman and Hart, 1980; Grossman, 1981; Milgrom, 1981). ${ }^{1}$ In the flexible language regime, the receiver's belief that a sender's type is the lower bound of the message sent is self-fulfilling (Milgrom and Roberts, 1986). Again, all information is revealed in equilibrium.

However, the arguments for the full revelation of information and the irrelevance of language crucially depend on a high degree of strategic sophistication on behalf of the receiver. In reality, many receivers may be naive and struggle to be maximally skeptical in the face of nondisclosure or vague messages. Building on Milgrom and Roberts (1986), Eyster and Rabin (2005) and Hagenbach and Koessler (2017), our model therefore features both sophisticated and naive receivers. ${ }^{2}$ When a naive receiver encounters nondisclosure, she estimates that the sender is the average type. When she encounters a vague message, she estimates that the sender's type is the average of the sent interval.

The presence of naive receivers drives both nondisclosure (under precise language) and the exploitative deployment of vague messaging (under flexible language). Vague messages take the following simple form. Senders send an interval that spans their actual type and the upper bound of the message space.

Moving from the flexible language regime to the precise language regime then implies

\footnotetext{
${ }^{1}$ The highest type discloses because the disclosed information definitely exceeds receiver expectations. Because nondisclosure now cannot stem from the highest type, the second highest type is compelled to disclose. An iteration of this reasoning yields full disclosure.

${ }^{2}$ These other papers derive many of the behavioral predictions we test in the experiment. Our theoretical contribution lies in deriving novel welfare results.
} 
a trade-off. There is more frequent disclosure in the flexible language regime and more precise disclosure in the precise language regime. Sophisticated receivers, who are not fooled by vagueness, form more accurate beliefs under flexible language. Naive receivers form more accurate beliefs under precise language. Importantly, information transmission, i.e. the average accuracy of receivers' beliefs, is higher under precise language, irrespective of the proportion of naive receivers.

The Experiment. The experiment compares a FlEXIBLE and a Precise treatment that reflect the distinction between the two language regimes in the model. In both treatments, a sender's type is uniformly distributed over the integers from 0 to 5 . A sender in the FlexiBle treatment can disclose any interval containing her actual type. For example, a sender with type 2 could disclose that her type belongs to the interval between 2 and 5 . A sender in the PRECISE treatment can only disclose her exact type or nothing.

The theoretical predictions are generally borne out in the experimental data. Senders disclose more in Flexible than in Precise. In Flexible, senders use vague messages. Moreover, the exact form of the modal message we observe is remarkably close to the one predicted by the model. Our PRECISE treatment replicates the results by Jin et al. (2018b): we find that sender behavior reflects a threshold equilibrium in which only high types disclose. A minority of senders in both treatments does not behave according to the theoretical predictions.

Validating the model's key assumption, we find strong evidence for the existence of two distinct receiver types, i.e. naives and sophisticates. We categorize receivers as either sophisticated or naive on the basis of their guesses. We find that the average naive receiver makes fewer mistakes in PRECISE. Depending on the specification, the average sophisticated receiver makes more mistakes or no fewer mistakes in PRECISE.

Finally, when receivers encounter rational senders, information transmission is higher in PREcise. Let us be maximally precise in our disclosure and note that there is no treatment effect on average information transmission in the raw data. This null result is 
driven by a few senders' irrational decision, unbalanced across treatments, not to disclose a high type. However, information transmission is significantly higher in PRECISE once we restrict the sample to the two thirds of senders that conform exactly with the theory or once we eliminate the 12 (out of 1185) observations that feature a sender of the highest type who remains silent.

Policy implications. In contrast to most field settings, the experimental laboratory affords us the opportunity to exogenously vary the language at a sender's disposal. Moreover, whereas most field studies have to infer receivers' beliefs from sender behavior or other outcomes, our dataset allows us to characterize the exact nature of receivers' misinference. As a result, our treatment comparison can shed light on how policies that impose precise language on senders are likely to affect information transmission.

Such policies are possible for all of our motivating examples and often feasible where mandatory disclosure is not (see section 4 for a discussion). In some settings, they are already in place. For example, the well-known and widely-used independent German certifier of consumer products, Stiftung Warentest, gives products and services a precise mark and a vague summary category like "very good". It imposes precise language by legally requiring disclosures of its certification to contain the precise product rating. Our results suggest that restricting flexibility improves average information transmission and redistributes rents to naive consumers.

The imposition of precise disclosure is also taking root in science. For example, publishing guidelines by the American Psychological Association require authors to disclose the exact p-value, effect size, degrees of freedom, and statistical test underlying a given result. Similarly, the field of economics has undergone a general move toward precise disclosure. For instance, authors of experimental studies increasingly commit to the exact specifications of statistical tests in pre-analysis plans and thereby, among other things, reduce the subsequent flexibility in presenting their research findings.

The self-incrimination clause of the fifth amendment of the United States constitution 
affords defendants the right not to testify against themselves in criminal cases. ${ }^{3}$ In settings in which lying is impossible (because testimony has to be backed up by hard evidence) or undesirable (because the expected penalty of perjury exceeds its benefits) the defendant's choice between testifying in her own trial or "pleading the fifth" constitutes a voluntary disclosure game with the jury. Moreover, a majority of US courts take the position that voluntarily waiving the right against self-incrimination opens a defendant up to crossexamination on all issues relevant to the trial. ${ }^{4}$ The right not to self-incriminate therefore imposes precise voluntary disclosure. In an influential court ruling, the majority opinion argues against allowing the defendant to "decide how far he will disclose what he has chosen to tell in part [...]" because "it must be conceded that the privilege is to suppress the truth, but that does not mean that it is a privilege to garble it." ${ }^{5}$ Our results highlight a key distinction between suppressing the truth and garbling it by means of partial or vague disclosure and speak to the wisdom in prohibiting the latter.

Related Literature. The exploitation of flexibility in voluntary information disclosure has been documented for car sellers describing their cars on ebay (Lewis, 2011), business schools referring to third-party rankings (Luca and Smith, 2015), and researchers presenting their findings (Krawczyk, 2015; Brodeur et al., 2016). Relatedly, there is evidence that firms shroud (Brown et al., 2010), obfuscate (Ellison and Ellison, 2009) or complexify (Ru and Schoar, 2016) unfavorable information about their products. In markets where voluntary disclosure is necessarily precise, nondisclosure often ensues. For example, producers of salad dressings do not voluntarily disclose fat content if it is high (Mathios, 2000), poor health maintenance organizations do not obtain independent accreditations (Jin, 2005), and movie studios avoid pre-release screenings to critics if a movie's quality is low (Brown et al., 2012). However, data limitations in the field have thus far kept researchers from studying the causal impact of different language regimes on information transmission and

\footnotetext{
${ }^{3}$ See Amar and Lettow (1995) for a critical discussion of this privilege.

${ }^{4}$ See Yale Law Journal (1952) and Stanford Law Review (1962) for discussions of the waiver and how it has and should be interpreted by the law.

${ }^{5}$ See the opinion by judge Hand in United States v. St. Pierre, 132 F.2d 837 (2d circuit 1942).
} 
from characterizing the exact nature of receivers' misinference. ${ }^{6}$

Our paper builds on a small literature that studies information disclosure in the experimental laboratory. While no previous experiment compares voluntary disclosure under precise and flexible language, several studies relate to at least one of our treatments. Our precise language treatment follows Jin et al. (2018b), who provide evidence for both incomplete unraveling and receiver naivete. Earlier studies by Forsythe et al. (1989), King and Wallin (1991b) and Dickhaut et al. (2003) find evidence for full unraveling after a sufficiently high number of repetitions, albeit in a setting that features several receivers and auctioning mechanisms that potentially permit other explanations for players' behavior (Jin et al., 2018b). ${ }^{7}$

In an experiment that complements our findings in the flexible language treatment, Jin et al. (2018a) study a mandatory disclosure game in which senders can complexify their disclosure by revealing their type as the sum of a string of numbers. They find that low sender types make us of complexity and that some receivers are fooled by it because they are overconfident in their ability to interpret complex messages. In contrast, our results suggest that a lack of strategic sophistication leads to the loss in information transmission associated with vague disclosure. Hagenbach and Perez-Richet (2017) conduct an experiment that allows for vague messages. Instead of varying the language at a sender's disposal, they vary the sender's incentive structure. Like us, they find that types who wish to be perceived as another type are more likely to use partial or nondisclosure. They also find that receivers are better off under acyclical incentive structures, i.e. games in which masquerading incentives are not circular. An early experiment by King and Wallin (1991a) allows sellers in a double auction with several buyers to disclose precise as well as coarse information (i.e. an interval of fixed size). Where a seller's realized type and the available interval permit it, sellers frequently send an interval whose lower bound is their type. This

\footnotetext{
${ }^{6}$ See Dranove and Jin (2010) for a review of the theory and empirics of disclosure in economic applications and Loewenstein et al. (2014) for the psychological subtleties surrounding the analysis of disclosure games.

${ }^{7}$ Also see Benndorf et al. (2015) for an unraveling failure that is driven by senders' bounded rationality.
} 
has a flavor of the senders' strategies we uncover in the flexible language treatment.

Vague messages have been shown to arise in other strategic domains. Vagueness is a key ingredient of cheap talk communication (Crawford and Sobel, 1982), where messages are unverifiable and the interests of the sender and the receiver are typically at least partially aligned. In these games, vagueness arises in equilibrium even if all receivers are perfectly rational. In an experimental public good game, Serra-Garcia et al. (2011) find that vague communication can be socially valuable when truthful communication conflicts with efficiency. Agranov and Schotter (2012) show that a benevolent announcer may resort to vague announcements of payoff states to facilitate coordination in an experimental coordination game.

Finally, a series of papers following Gabaix and Laibson (2006) investigate the circumstances under which firms fail to educate their own and other firms' consumers about unfavorable product attributes or add-on costs (see Heidhues and Koszegi (2018) for a recent review of the broader behavioral industrial organization literature). However, the role of the flexibility of language in firms' communication with 'behavioral' consumers has been largely neglected.

Roadmap. In the next section, we present the model. Section 3 describes experimental design and results and section 4 discusses policy implications.

\section{The Model}

\subsection{Setup}

A sender $(S)$ and a receiver $(R)$ play a persuasion game in which $S$ aims at maximizing $R$ 's guess, while $R$ wants her guess to be as accurate as possible. When the state of nature is $\omega$ and $R$ 's guess is $g$, then $S$ 's payoff is $U_{S}=g$. R's payoff is $U_{R}=-(\omega-g)^{2}$, which implies that she finds it optimal to guess her expectation of the state. At the initial stage, 
$\omega$ is drawn from a continuous uniform distribution with support $\Omega=[0,1]{ }^{8} \quad S$ privately observes her type $\omega$ and sends a message $m$ before $R$ makes a guess.

Since $S$ cannot make false statements, her message must always include her true type. Beyond this common requirement, we consider two alternative communication regimes, which we refer to as precise and flexible language. Under precise language, the set of messages available to type $\omega$ is $\{\omega, \Omega\}$, i.e. $S$ can either reveal her type exactly $(m=\omega)$ or remain silent $(m=\Omega)$. Under flexible language, the set of messages available to type $\omega$ is the union of all compact subsets of $\Omega$ containing $\omega$, which also includes the option to remain silent. While we represent the choice to remain silent with the coarsest message (i.e. $m=\Omega$ ) for ease of notation, in our interpretation this is conceptually distinct from actively disclosing as in the case of other messages. Thus, we say that a given type discloses only when she sends a message that conveys at least some information even if interpreted at face value. Likewise, we measure the amount of disclosure as the probability that $S$ sends a message other than $m=\Omega$.

Key to the analysis is that $R$ may lack strategic sophistication. In particular, we take the posterior distribution of a fully naive $R$ to coincide with the prior truncated over types for which the message sent is available. Upon message $m=\Omega$, the posterior of a fully naive $R$ hence coincides with the prior, since that message is available to all types. Upon message $m=\omega$, her posterior is degenerate at $\omega$. And upon message $m=[a, b] \subset \Omega$ with $a>b$, her posterior is uniform on $[a, b]$. Receivers' insufficient skepticism may hence stem from a failure to take into account the dependence of a sender's strategy on her type, in the spirit of cursed equilibrium (Eyster and Rabin, 2005).

We assume that heterogeneity in sophistication is bimodal, as in Milgrom and Roberts (1986) and Hagenbach and Koessler (2017). In particular, we suppose that $R$ is fully naive with probability $\chi \in(0,1)$ and fully sophisticated with complementary probability. In Appendix B.1 we generalize the model by allowing for partially naive types and an arbitrary distribution of sophistication in the population.

\footnotetext{
${ }^{8}$ Appendix B.2 considers non-uniform priors.
} 
A pure strategy of $S$ specifies a message $m(\omega)$ based on her type. A pure strategy of $R$ specifies a guess for a sophisticated and a naive type, which we denote respectively by $g(m)$ and $g_{\chi}(m)$, based on $S$ 's message. Our solution concept is a natural adaptation of perfect Bayesian equilibrium which takes into account that $S$ 's message is hard evidence and that $R$ may not be fully strategic. In addition to the usual requirements, upon any off-the-equilibrium-path message, the support of $R$ 's posterior should not include any type for which that message is unavailable. Moreover, the guess of a naive $R$ must be optimal given her possibly wrong and at least partially exogenously given beliefs. Without loss of generality, we restrict our attention to pure strategy equilibria and adopt the convention that $S$ refrains from disclosing whenever indifferent.

\subsection{Predictions}

When language is flexible, $S$ elects to disclose an interval that spans her type and the highest type. As the equilibrium is necessarily fully separating, ${ }^{9}$ this strategy is optimal in that it maximally inflates the guesses of a naive $R$.

Proposition 1 (Equilibrium under flexible language). Under flexible language, in equilib$\operatorname{rium} m(\omega)=[\omega, 1], g([a, b])=a$ and $g_{\chi}([a, b])=(a+b) / 2 .{ }^{10}$

Proof. See Milgrom and Roberts (1986).

When language is precise, $S$ finds it optimal to disclose if and only if her type is sufficiently high. The marginal sender is indifferent between perfectly revealing her type and remaining silent, which induces a higher guess from a naive $R$ (the prior mean) but a lower guess from a sophisticated $R$ (the average silent type). Then, higher types indeed

\footnotetext{
${ }^{9}$ The reason for why full separation necessarily obtains is that, for any candidate equilibrium pooling message, the highest type in the pool always has access to another message that would strictly raise the guess of both a sophisticate and a naive $R$.

${ }^{10}$ While the beliefs and guesses of a sophisticated $R$ upon off-the-equilibrium-path messages are not uniquely pinned down, without loss of generality we adopt the convention that these take the same form as in the case of on-the-equilibrium-path messages.
} 
find it optimal to disclose and lower types to remain silent. Also, the disclosure cutoff is lower than the prior mean and increases with the proportion of naives.

Proposition 2 (Equilibrium under precise language). Under precise language, there exists a unique cutoff $\omega^{*}=\frac{\chi}{1+\chi}$ such that in equilibrium:

$$
m(\omega)=\left\{\begin{array}{c}
\omega \text { if } \omega>\omega^{*} \\
\Omega \text { if } \omega \leq \omega^{*}
\end{array} ; \quad g(m)=\left\{\begin{array}{c}
\omega \text { if } m=\omega \\
\frac{\omega^{*}}{2} \text { if } m=\Omega
\end{array} ; \quad g_{\chi}(m)=\left\{\begin{array}{l}
\omega \text { if } m=\omega \\
\frac{1}{2} \text { if } m=\Omega
\end{array} .\right.\right.\right.
$$

Proof. See Eyster and Rabin (2005). ${ }^{11}$

Comparing the two equilibrium outcomes, we can derive the following predictions about differences in players' behavior between the flexible and precise language regime.

Proposition 3 (Predictions on differences in behavior). For any given $\chi \in(0,1)$

\section{Sender behavior:}

(a) there is more disclosure under flexible than under precise language;

(b) the average disclosing type is higher under precise than under flexible language.

\section{Receiver behavior:}

(a) $R$ 's expected guess is lower under precise than under flexible language and in both cases it exceeds $S$ 's expected type;

(b) under both precise and flexible language $R$ 's expected guess increases with $\chi$.

Proof. See section A.1 in the appendix.

Predictions on senders' behavior hinge on the fact that all types disclose under flexible language while only sufficiently high types disclose under precise language. Predictions on receivers' behavior are driven by the guesses of a naive $R$, since, given the Bayesian consistency of rational beliefs, the average guess of a sophisticated $R$ always coincides with

\footnotetext{
${ }^{11}$ In Eyster and Rabin (2005), the cutoff is $\omega^{*}=\frac{1}{1+\chi}$ and it types below who disclose, since $S$ 's payoff is decreasing in $R$ 's guess. Also, as detailed in Appendix B.1, $R$ 's naivete takes a slightly different form.
} 
the prior mean. For any realization of $S$ 's type, the guess of a naive $R$ is higher under flexible than under precise language, which explains the first part of prediction 2a, and always equal or higher than $S$ 's type, which explains the second part. The average guess of a naive is therefore higher than that of a sophisticate, which entirely drives prediction $2 \mathrm{~b}$ under flexible language. Under precise language, it is also the case that the average guess of a naive increases with $\chi$ since, as $S$ discloses less often, the set of $S$ 's types she overestimates increases.

To consider players' welfare, recall that the expected utility of $S$ is simply the guess she expects to induce in $R$, while the expected utility of $R$ is the accuracy of her guess measured by the mean squared error. ${ }^{12}$ For a sophisticated $R$, this error boils down to the expected residual variance upon $S$ 's disclosure. For a naive $R$, the error also incorporates the systematic bias in her updating that $S$ 's strategy introduces. Throughout, we will use the terms $R$ 's expected payoff and information transmission interchangeably. Moreover, the ex-ante and ex-post qualifications refer respectively to whether the expectation is computed unconditionally or conditionally on the player in question having observed her type (i.e. the state for $S$ and the sophistication level for $R$ ).

Proposition 4 (Predictions on differences in payoffs). For any given $\chi \in(0,1)$

\section{Sender payoff:}

(a) the ex-ante expected payoff of $S$ is higher under flexible language than under precise language;

(b) this is also true ex-post if and only if $S$ 's type is not too low (in particular, it is true for all types who disclose under precise language).

\section{Receiver payoff:}

\footnotetext{
${ }^{12}$ While in our setting $R$ 's preference ranking over flexible and precise language can only be defined with respect to a specific loss function, our results are robust to common alternative measures. When we present our experimental data we therefore use the absolute mean error, which is more directly interpretable in that it assigns no heavier relative penalty to larger errors.
} 
(a) the ex-ante expected payoff of $R$ is higher under precise than under flexible language;

(b) ex-post, the expected payoff of a sophisticated $R$ is higher under flexible language and the expected payoff of a naive $R$ is higher under precise language.

Proof. See section A.2 in the appendix.

Ex ante, $S$ always prefers flexible language because it allows her to more strongly inflate the expectation of a naive $R$ and it also offers more opportunities to do so. In spite of this, sufficiently low types still prefer precise language ex post, since it allows them to pool with higher types even in the eyes of a sophisticate. By the same token, a naive $R$ prefers precise language, since it limits the scope for deceiving her, while a sophisticated $R$ prefers flexible language, since it allows her to always perfectly infer the state.

The difference in the preference of sophisticates and naives for precise and flexible language has been noted by Hagenbach and Koessler (2017). ${ }^{13}$ In the appendix we show that this result, obtained in a setting of two extreme levels of sophistication, naturally extends to settings where sophistication varies continuously in the population (proposition B.1). More importantly, our setting allows us to sign the overall effect of language on $R$ 's payoffs: $R$ prefers precise language. Intuitively, since a naive $R$ is deceived more frequently and more severely under flexible language, the resulting loss has a substantially larger magnitude than the loss of both a naive and a sophisticate under precise language. Given the opposing language preferences of naives and sophisticates, one may think that $R$ 's ex-ante welfare could be higher under flexible language if the population of receivers is mostly sophisticated. This is not the case because the presence of more sophisticates also disciplines $S$ 's disclosure behavior under precise language (i.e. as $\chi$ goes to zero, so does the disclosure cutoff $\omega^{*}$ ), which fosters information transmission to both sophisticates and naives.

\footnotetext{
${ }^{13}$ Our precise and flexible regimes correspond respectively to simple and rich language in the terminology of Hagenbach and Koessler (2017).
} 
In Appendix B.1, we show that $R$ 's preference for precise language is robust to arbitrary distributions of naivete in the population. In Appendix B.2, we use numerical simulations to demonstrate that it holds for a large class of non-uniform priors over the state. There, we also provide some quantitative measure of $R$ 's welfare gains from precise language and build some more intuition behind this result by identifying the features of prior distributions that can give rise to rare counterexamples.

\section{The Experiment}

\subsection{Design}

The experiment was programmed in zTree (Fischbacher, 2007). A total of 158 subjects participated in 8 sessions at the Munich Experimental Laboratory for Economic and Social Sciences (MELESSA) in the spring of $2017 .{ }^{14}$ One session lasted for about 45 minutes and the average earnings (including a $€ 4$ show-up fee) were $€ 15.05$, with minimum earnings of $€ 5.90$ and maximum earnings of $€ 23.50$. The instructions were read aloud by the experimenter. Screenshots of the decision screens are gathered in Appendix E and instructions and payoff tables can be found in Appendix F.

The experiment featured a between subject design that compared two variants of a disclosure game. At the beginning of the experiment, subjects in both treatments were randomly assigned to the role of a sender or the role of a receiver. A subject remained in her assigned role for the duration of the experiment. All subjects played 15 rounds of the disclosure game. In each round, a subject played the game with a randomly selected anonymous partner in the opposite role.

It was common knowledge that a sender's type $\omega$ was drawn in each round from the set $\{0,1,2,3,4,5\}$ and that each type was equally likely. After privately observing her type, a sender decided on a message to send to the receiver. Our two treatments differed only in

\footnotetext{
${ }^{14}$ We piloted our design with 58 subjects in the winter of 2016 . Here we organized the treatment variation in a within-subject fashion and find similar results.
} 


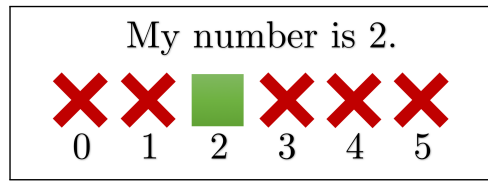

(a) Precise message

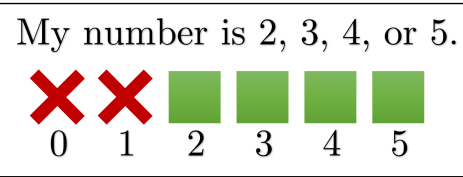

(b) Vague message

Figure 1 Examples of messages

the type of messages senders were able to send.

In the FLEXIBLE language treatment (80 subjects), the sender was allowed to send any interval containing her type. ${ }^{15}$ In the PRECISE language treatment (78 subjects), the sender could either disclose her precise type or do not disclose. In FLEXIBLE, senders were therefore able to send vague messages and while any feasible message in PRECISE was also feasible in FlEXIBLE, the reverse was not true. In the case of nondisclosure, the receiver was notified that "the sender did not send a message" in both treatments. Figure 1 depicts two messages a sender of type 2 might send in the different treatments.

After seeing the sender's message, the receiver stated her guess about the sender's type, i.e. $g \in\{0,0.5, \ldots, 4.5,5\}$. While the sender was incentivized to induce the highest possible guess in the receiver, the receiver was paid for accuracy. Subjects were paid in probability points and for a single randomly selected round. After each round, subjects received information about the receiver's guess, the sender's type and the probability points they earned.

A receiver's points depended on her guess and the sender's type as follows

$$
p_{R}=\frac{110-20\left|\frac{\omega-g}{1.37}\right|^{1.4}}{110}
$$

A sender's points depended only on the receiver's guess:

$$
p_{S}=\frac{110-20\left|\frac{5-g}{1.37}\right|^{1.4}}{110}
$$

\footnotetext{
${ }^{15}$ While sending an interval that contains all possible types was not allowed, the equivalent strategy of nondisclosure was always at a sender's disposal.
} 
The probability points $p$ a subject earned in the payoff-relevant round then determined the likelihood of winning a $€ 8$ prize. For example, a subject in the receiver role was paid according to a lottery that yielded a relatively high prize of $€ 8$ with probability $p_{R}$ and a lower prize of $€ 1$ with the complementary probability $1-p_{R}$. Paying subjects in probability points makes them less liable to the influence of risk preferences (Roth and Malouf, 1979; Hossain and Okui, 2013; Harrison et al., 2014). To make sure that subjects understood the incentive structure we provided them with payoff tables that mapped any constellation of receiver guess and sender type into the relevant probability points and let them solve comprehension tasks before the experiment.

After the main part of the experiment, we asked senders to state the distribution of receiver guesses upon nondisclosure in the pilot experiment. Similarly, we asked receivers to state the belief distribution over non-disclosed sender types. In additional unincentivized elicitations in FLEXIBLE, we asked senders about the average receiver guess in the pilot session after receiving the messages $\{1,2,3,4,5\},\{2,3,4,5\},\{3,4,5\}$, and $\{4,5\}$ and receivers about the most likely message of all six possible sender types. ${ }^{16}$ Finally, a post-experimental survey collected some additional sociodemographic data.

\subsection{Results}

We first describe participants' behavior in the two treatments and then analyze information transmission. Our analysis is based on data that pools observations across rounds. Appendix $\mathrm{C}$ provides results on how player behavior evolves over time. For all statistical tests we report p-values from a two-sided t-test that comes from a regression-based approach with robust standard errors clustered at the subject level.

\footnotetext{
${ }^{16}$ In the incentivized elicitations, subjects were paid for being close to a variable's empirical distribution in the pilot sessions. We find that subjects' "out-of-sample" beliefs generally reflect their beliefs and behavior in the experiment, so we do not analyze them separately in what follows.
} 


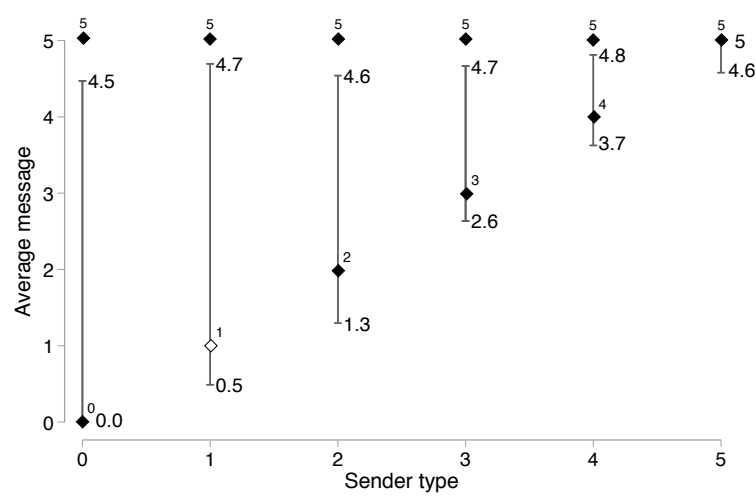

(a) Messages

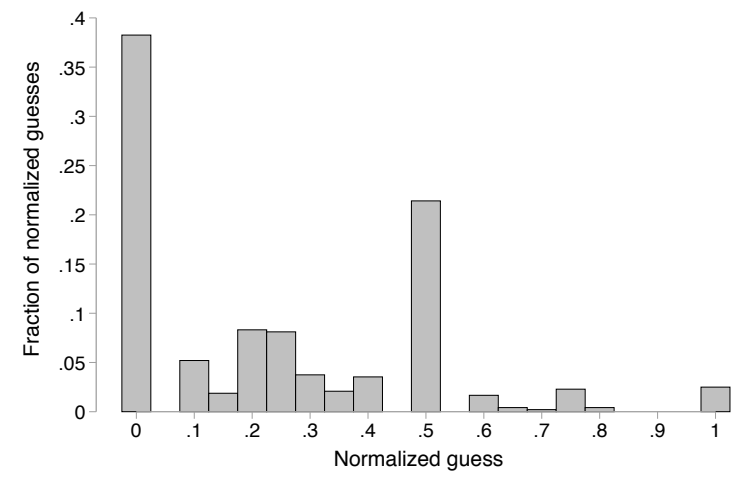

(b) Normalized guesses

Figure 2 Behavior in Flexible: (a) Solid lines show the avg. lower and upper bounds of all messages sent; hollow diamonds show the model's point predictions; if a diamond is black, then the prediction coincides with the modal message. Average and modal messages include nondisclosure.

\subsubsection{Behavior}

Flexible Language Treatment. According to the theory, a sender in the Flexible treatment discloses an interval that spans her type and the upper bound of the type space. Figure 2a depicts the average lower and upper bounds of the messages sent by different sender types. Observed messages are in line with the predictions of the model. Upper bounds are close to the highest type and lower bounds increase with the type. Modal messages, also depicted in the figure, almost perfectly coincide with the theory's predictions. The only exception is provided by senders of type 1, who remain silent more often than they send their predicted message.

As a first step toward analyzing receiver behavior, we normalize guesses. Given a guess $g$ and a message with lower bound $\underline{\omega}$ and upper bound $\bar{\omega}>\underline{\omega}$, the normalized guess is

$$
g_{n}=\frac{g-\underline{\omega}}{|\bar{\omega}-\underline{\omega}|}
$$

The normalization allows for the comparison of guesses induced by different messages. Normalized guesses range from 0 to 1 and are only defined for non or vague disclosure. A fully naive normalized guess takes a value of 0.5 . The theoretical prediction for a sophisticated normalized guess in FLEXIBLE is 0. 


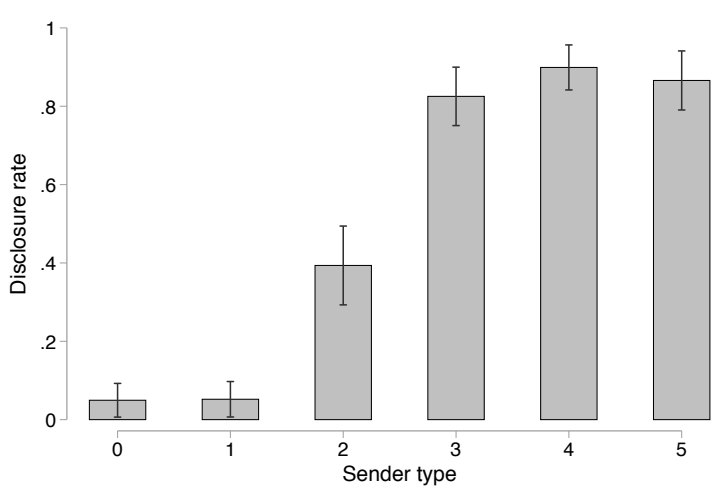

(a) Disclosure rates

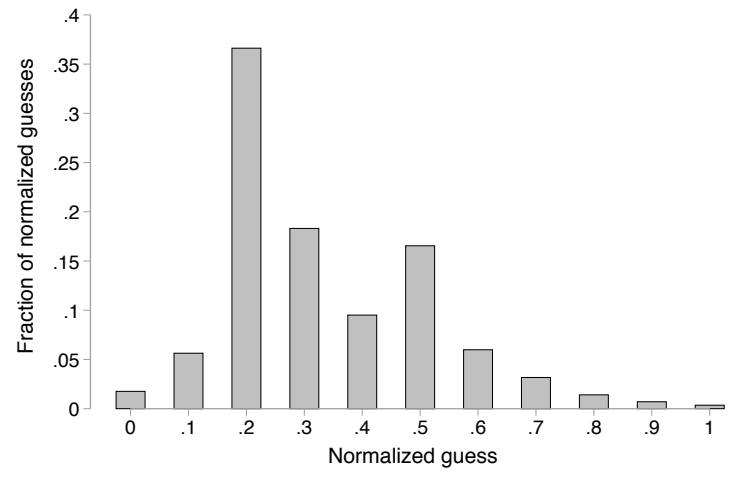

(b) Normalized guesses

Figure 3 Behavior in Precise: Graph (a) shows 95\% confidence intervals around the avg. disclosure rates.

Figure $2 \mathrm{~b}$ shows the distribution of normalized guesses. The bimodal distribution with mass points at 0 and 0.5 vindicates our model's assumption that there are two distinct receiver types: sophisticates and fully naive receivers. ${ }^{17}$ We find that receivers' average belief upon observing nondisclosure or receiving a vague message is upwardly biased. While the average normalized guess is at about 0.25 , senders' average normalized type is significantly lower at $0.13(p$-value $<0.001) .{ }^{18}$ Instead, all receivers are able to rationally interpret singleton intervals, i.e. a precisely disclosed type.

Precise Language Treatment. In the presence of naive receivers, our model predicts that precise language will give rise to a threshold equilibrium with nondisclosure on behalf of low types and disclosure on behalf of types above the threshold. Figure 3a depicts disclosure rates by sender type. In line with an equilibrium threshold of around 2, the disclosure rate is almost zero for the lowest two types, 40 percent for type 2 , and above 80 percent for the highest three types. Note that disclosure rates of less than 100 percent for the highest types imply a slight departure from our hypothesis of sender rationality. ${ }^{19}$

All receivers are able to rationally interpret a precisely disclosed type. Figure 3b depicts

\footnotetext{
${ }^{17}$ We can reject the null hypothesis of unimodality using the Dip Test introduced by Hartigan and Hartigan (1985) $\left(p_{\text {Dip }}\right.$-value $\left.<0.001\right)$.

${ }^{18}$ The normalized type is the sender counterpart of the normalized guess and is given by $\omega_{n}=\frac{\omega-\underline{\omega}}{|\bar{\omega}-\underline{\omega}|}$.

${ }^{19}$ However, after the initial five rounds the disclosure rate of high types increases markedly, e.g., for sender type 5 , it increases from 70.8 percent to 92.9 percent.
} 
the distribution of normalized receiver guesses upon nondisclosure. We observe a bimodal distribution with mass points around 0.2 and at $0.5 .{ }^{20}$ Because of the threshold strategy, the sophisticated guess upon nondisclosure is now larger than zero. In particular, a receiver's empirical best response is equal to the average non-disclosing type, whose normalized value is equal to 0.25 . Therefore, the histogram's first mode reflects the accurate beliefs of sophisticated receivers, whereas the second mode corresponds to the beliefs of a fully naive receiver.

Receivers average normalized guess upon observing nondisclosure is 0.33 , which reflects a significant overestimation of the average normalized non-disclosed type of 0.25 ( $p$-value $=0.007)$.

Treatment Comparison. Disclosure rates are higher in FLEXIBLE, where senders disclose 75 percent of the time, than in PRECISE, where they disclose 51.5 percent of the time $(p$-value $<0.001)$. This result seems to be driven by differences in disclosure strategies, as the average disclosing sender type is significantly higher in PRECISE than in FLEXIBLE $(3.59$ versus $3.08 ; p$-value $<0.001){ }^{21}$

We observe that the average receiver guess is slightly lower under PRECISE than under Flexible (2.66 in Precise versus 2.85 in Flexible; $p$-value $=0.095$ ). This difference indicates that, as the theory predicts, the average sender is better off in FLEXIBLE.

\subsubsection{Information transmission}

We measure information transmission by receivers' mistakes, which themselves are given by the absolute difference between a receiver's guess and a sender's type. Perfect information transmission corresponds to a mistake of zero.

\footnotetext{
${ }^{20}$ We can reject the null hypothesis of unimodality using a Dip Test $\left(p_{\text {Dip }}\right.$-value $\left.<0.001\right)$.

${ }^{21}$ Although not significantly different, results also agree with the predicted direction for the differences in average non-disclosing types: 1.26 in PRECISE treatment versus 1.07 in FLEXIBLE language ( $p$-value $=0.310$ ).
} 
Overall information transmission. Our model predicts that average receiver mistakes are lower in PRECise. Table 1 shows the determinants of receivers' mistakes. Column 1 depicts an OLS regression of receiver mistakes on the treatment and tells us that the treatment effect of PRECISE on average mistakes is negative, but insignificant. The insignificance of the treatment effect is driven by the minority of sender choices that do not conform to our theoretical predictions. To test this hypothesis, we restrict the sample to the 828 observations that feature theory-conforming sender behavior. In FLEXIBLE, such behavior takes the form of a message that spans the sender's type and 5. In PRECISE, it takes the form of a threshold strategy, whereby only types of 2 or higher disclose. Here, the threshold of 2 is the best response to the distribution of receiver guesses upon nondisclosure.

Column 2 focuses on only those interactions in which the sender behavior conforms $e x-$ actly to the theory. In these cases, restricting our senders to the use of PRECISE language leads to lower average receiver mistakes. The significant treatment effect emerges because our data restriction eliminates a very small number of outlier observations driven by sender mistakes that disproportionately occurred in PRECISE. ${ }^{22}$ Imposed precision therefore improves information transmission in the absence of pronounced sender irrationality that is unbalanced across language regimes.

A typology of players. The theory predicts that moving from FlEXIBLE to PRECISE decreases the average mistakes made by naive receivers and increases the average mistakes made by sophisticated receivers. A corollary of this prediction is that the interaction effect of imposed precision and a receiver's naivete on mistakes is negative. In order to test these predictions, we use our experimental data to classify receivers as naives and sophisticates.

A normalized guess is fully naive if it is equal 0.5. We arrive at our measure of individual receiver naivete by dividing the number of rounds in which the receiver stated a fully naive guess by the number of rounds in which the receiver did not encounter precise

\footnotetext{
${ }^{22}$ In particular, the treatment effect on average information transmission is also significant at the 10 percent level if we merely drop the 12 observations ( 1 percent of total observations) that feature a sender of type 5 who does not disclose and thereby generates a disproportionately large outlier receiver mistake. 11 of these observations occurred in PRECISE.
} 


\begin{tabular}{|c|c|c|c|c|c|c|}
\hline Dep. variable: & $\begin{array}{c}(1) \\
\text { Mistake }\end{array}$ & $\begin{array}{c}(2) \\
\text { Mistake }\end{array}$ & $\begin{array}{c}(3) \\
\text { Mistake }\end{array}$ & $\begin{array}{c}(4) \\
\text { Mistake }\end{array}$ & $\begin{array}{c}(5) \\
\text { Mistake }\end{array}$ & $\begin{array}{c}(6) \\
\text { Mistake }\end{array}$ \\
\hline Precise (d) & $\begin{array}{l}-0.0610 \\
(0.0676)\end{array}$ & $\begin{array}{c}-0.159^{* *} \\
(0.0746)\end{array}$ & $\begin{array}{c}-0.252^{* * *} \\
(0.0754)\end{array}$ & $\begin{array}{c}-0.231^{* *} \\
(0.0856)\end{array}$ & $\begin{array}{c}0.140^{*} \\
(0.0787)\end{array}$ & $\begin{array}{c}0.0250 \\
(0.0826)\end{array}$ \\
\hline Round & $\begin{array}{c}-0.0298^{* * *} \\
(0.00582)\end{array}$ & $\begin{array}{c}-0.0207^{* * *} \\
(0.00498)\end{array}$ & $\begin{array}{c}-0.0331^{* * *} \\
(0.00995)\end{array}$ & $\begin{array}{c}-0.0342^{* * *} \\
(0.00871)\end{array}$ & $\begin{array}{c}-0.0257^{* * *} \\
(0.00674)\end{array}$ & $\begin{array}{c}-0.00932 * \\
(0.00465)\end{array}$ \\
\hline Constant & $\begin{array}{c}1.647^{* * *} \\
(0.106)\end{array}$ & $\begin{array}{c}1.742^{* * *} \\
(0.120)\end{array}$ & $\begin{array}{c}2.168^{* * *} \\
(0.165)\end{array}$ & $\begin{array}{c}2.322^{* * *} \\
(0.162)\end{array}$ & $\begin{array}{c}1.259^{* * *} \\
(0.115)\end{array}$ & $\begin{array}{c}1.277^{* * *} \\
(0.130)\end{array}$ \\
\hline Type dummies & Yes & Yes & Yes & Yes & Yes & Yes \\
\hline Incl. sender choices & All & $\begin{array}{l}\text { Theory- } \\
\text { conforming }\end{array}$ & All & $\begin{array}{l}\text { Theory- } \\
\text { conforming }\end{array}$ & All & $\begin{array}{l}\text { Theory- } \\
\text { conforming }\end{array}$ \\
\hline Incl. receivers & All & All & Naives & Naives & Soph. & Soph. \\
\hline$R^{2}$ & 0.172 & 0.456 & 0.331 & 0.605 & 0.135 & 0.454 \\
\hline Observations & 1185 & 828 & 510 & 360 & 675 & 468 \\
\hline
\end{tabular}

Table 1 OLS regressions of the treatment effect on receivers' absolute mistakes; robust standard errors clustered at the subject level in parentheses; ${ }^{*} p<0.10,{ }^{* *} p<0.05,{ }^{* * *} p<0.01$.

disclosure. If this ratio is smaller than 0.15 , then we say that a receiver is "hardly ever naive" or sophisticated. Otherwise, a receiver is deemed naive. Applying this classification procedure, we find that 57 percent of the receivers in our sample are sophisticated. ${ }^{23}$

Columns 3 and 4 of Table 1 repeat the regression models of columns 1 and 2, but include only naive receivers. Regardless of whether or not we only include theory-conforming sender behavior, the treatment effect on naive receivers is negative and significant. In column 5 , we see that, as the theory predicts, the treatment effect on sophisticated receiver's mistakes is positive and weakly significant. However, the result is not robust to considering only theory-conforming sender behavior and therefore disappears in column 6 .

In Appendix D we repeat the regressions in columns 3 through 6 for several alternative classifications of naivete and sophistication, including subjects' high school math grade and various notions of empirical best response. In the majority of specifications, naive receivers

\footnotetext{
${ }^{23}$ The fraction of naive receivers is higher in PRECISE (61.5 percent) than in FLEXIBLE (52.5 percent). However, this difference is not robust to different classification criteria. In general, the proportion of naives is slightly higher in PRECISE if the classification is based on the frequency of fully naive choices (as in our main classification) and slightly lower if the classification is based on the proximity to best-response behavior, as in Appendix D. Therefore, there is no reason to suspect that the treatment effect on overall information transmission is driven by differences in the proportion of naives across treatments.
} 
make significantly smaller mistakes under precise language and sophisticated receivers make insignificantly larger mistakes under precise language. The appendix also shows that the data bears out the corollary of our model's predictions: for all classifications, moving from flexible to precise language leads to relatively smaller mistakes for naive receivers, i.e. the interaction effect between the precise treatment and naivete on mistakes is negative.

\section{Discussion}

Our model and experimental data suggest that information transmission can be increased by restricting senders' flexibility in disclosing private information to receivers. Moreover, we find that a move to precise voluntary disclosure is likely to disproportionally benefit naive receivers. Since sophisticated receivers are (weakly) harmed by restricting flexibility, while naive receivers benefit, it is tempting to think that the effect of restricting flexibility on average receiver welfare is generally negative when there are many sophisticated receivers. However, this intuition is wrong: restricting flexibility improves information transmission for a broad class of distributions of strategic sophistication. When there are many sophisticates, precise language features (almost) full disclosure and still beats out the flexible language regime.

We have analyzed the disclosure game through the lens of sender rationality. In terms of the applications we have in mind, it is plausible that professional marketers are able to make cunning disclosure decisions and that high-paid attorneys are able to advise their clients on optimal disclosure strategies. And while senders and receivers are often drawn from the same population in the case of research, authors of papers naturally devote substantially more time and cognitive resources to a paper than a paper's readership is able to. Our theoretical results can accommodate and are robust to some sender irrationality. However, as our experiment shows, noisy behavior on behalf of senders can make it difficult to detect the benefits of precise disclosure in the experimental laboratory.

In our simple framework, an easy way to facilitate information transmissions is to 
legislate the mandatory disclosure of information. Where mandatory disclosure is feasible and unproblematic, our results suggest that it is crucial to also legislate precise language. However, for a number of reasons mandatory precise disclosure may often be infeasible or undesirable where the mere imposition of precision is not.

First, mandatory disclosure may be deemed unfair. Consider a policy maker's decision to regulate the disclosure of college rankings by colleges. While informative, rankings also contain an element of subjectivity and may be subject to dimensions, like students' entertainment facilities, that a college reasonably neglects. Therefore, it may be deemed unfair and invite resistance to force a college's disclosure of a given ranking. Nonetheless, conditional on a college's voluntary disclosure, imposing precision by prohibiting disclosure in selectively broad categories (e.g. "top 30") is likely to be less contentious. Concerns about fairness are also at the heart of arguments in favor of the self-incrimination clause of the fifth amendment.

Second, it may be prohibitively onerous for a regulator to determine whether a firm chose nondisclosure or simply lacked information. Consider a pharmaceutical company that tests one of its products only to find that the product has the unfortunate side effect of hair loss in 9 percent of the study's participants. In the case of nondisclosure, it may be hard for the regulator to find out whether a study was ever conducted. However, a press release that claims that "less than 10 percent" or "a small minority" of participants experienced hair loss could easily be flagged for vagueness.

Third, mandatory disclosure may yield perverse incentives. For example, consider a defendant's right not to self-incriminate. In its absence, law enforcement has an incentive to use coercion or even torture to extract an admission of guilt. In the case of markets, Matthews and Postlewaite (1985) and Polinsky and Shavell (2010) demonstrate that forcing firms to reveal their private information may ultimately hamper information transmission once firms' incentives to acquire information are taken into account.

The question of how the presence of naive receivers affects information transmission when senders are not exogenously endowed with private information about their type is 
an interesting avenue for future research. In particular, it is plausible that mandating precise language has a disincentive effect on information acquisition, given that it sets a limit on senders' ability to use information to deceive receivers. This would limit the benefits of imposing precision. At the same time, in other settings, flexible language may be even more harmful than our data suggests. Cain et al. (2005) show that the disclosure of a conflict of interest can lead advisors to give more biased advice by making them feel morally licensed to pursue their private goals. Because flexible language leads to both less information transmission and more disclosure (i.e. moral licensing), it may lead both to a greater underappreciation of an advisor's conflict of interest and to poorer advice.

Our results pertain to information transmission to an average receiver. But the ultimate desirability of precise language may hinge on the weight society attaches to different receiver types. For example, in the case of research, society may deem that information transmission to referees, who are mostly sophisticated, is initially more important than information transmission to the general public, who is more likely to be naive. Yet researchers may write up their findings in an attempt to persuade both of these audiences. It may then be the case that flexible language and its superior information transmission to sophisticated receivers ought to be favored.

Finally, it is not always clear-cut how information transmission maps into welfare in specific applications. For instance, Ispano and Schwardmann (2018) show that when firms compete for sophisticated and naive consumers through quality disclosure and pricing, wrong beliefs on behalf of consumers need not imply inefficient purchasing decisions. Relatedly, consumers might simply enjoy thinking of the Bordeaux region while drinking a blended wine from Roussillon.

\section{References}

Agranov, Marina and Andrew Schotter, "Ignorance is bliss: an experimental study of the use of ambiguity and vagueness in the coordination games with asymmetric payoffs," 
American Economic Journal: Microeconomics, 2012, 4 (2), 77-103.

Amar, Akhil Reed and Renee B Lettow, "Fifth Amendment First Principles: The Self-Incrimination Clause," Michigan Law Review, 1995, 93 (5), 857-928.

Benndorf, Volker, Dorothea Kübler, and Hans-Theo Normann, "Privacy concerns, voluntary disclosure of information, and unraveling: An experiment," European Economic Review, 2015, 75, 43-59.

Brodeur, Abel, Mathias Lé, Marc Sangnier, and Yanos Zylberberg, "Star wars: The empirics strike back," American Economic Journal: Applied Economics, 2016, 8 (1), 1-32.

Brown, Alexander L, Colin F Camerer, and Dan Lovallo, "To review or not to review? Limited strategic thinking at the movie box office," American Economic Journal: Microeconomics, 2012, 4 (2), 1-26.

Brown, Jennifer, Tanjim Hossain, and John Morgan, "Shrouded attributes and information suppression: Evidence from the field," Quarterly Journal of Economics, 2010, 125 (2), 859-876.

Cain, Daylian M, George Loewenstein, and Don A Moore, "The dirt on coming clean: Perverse effects of disclosing conflicts of interest," The Journal of Legal Studies, $2005,34(1), 1-25$.

Crawford, Vincent $\mathbf{P}$ and Joel Sobel, "Strategic information transmission," Econometrica, 1982, pp. 1431-1451.

Dickhaut, John, Margaret Ledyard, Arijit Mukherji, and Haresh Sapra, "Information management and valuation: an experimental investigation," Games and Economic Behavior, 2003, 44 (1), 26-53.

Dranove, David and Ginger Zhe Jin, "Quality disclosure and certification: Theory and practice," Journal of Economic Literature, 2010, 48 (4), 935-963. 
Ellison, Glenn and Sara Fisher Ellison, "Search, obfuscation, and price elasticities on the internet," Econometrica, 2009, 77 (2), 427-452.

Eyster, Erik and Matthew Rabin, "Cursed equilibrium," Econometrica, 2005, 73 (5), $1623-1672$.

Fischbacher, Urs, "z-Tree: Zurich toolbox for ready-made economic experiments," $E x$ perimental Economics, 2007, 10 (2), 171-178.

Forsythe, Robert, R Mark Isaac, and Thomas R Palfrey, "Theories and tests of "blind bidding" in sealed-bid auctions," The Rand Journal of Economics, 1989, pp. 214238.

Gabaix, Xavier and David Laibson, "Shrouded attributes, consumer myopia, and information suppression in competitive markets," The Quarterly Journal of Economics, $2006,121(2), 505-540$.

Grossman, Sanford J, "The informational role of warranties and private disclosure about product quality," The Journal of Law and Economics, 1981, 24 (3), 461-483.

_ and Oliver D Hart, "Disclosure laws and takeover bids," The Journal of Finance, 1980, 35 (2), 323-334.

Hagenbach, Jeanne and Eduardo Perez-Richet, "Communication with Evidence in the Lab," Working Paper 2017.

_ and Frédéric Koessler, "Simple versus rich language in disclosure games," Review of Economic Design, 2017, pp. 1-13.

Harrison, Glenn W, Jimmy Martínez-Correa, and J Todd Swarthout, "Eliciting subjective probabilities with binary lotteries," Journal of Economic Behavior \& Organization, 2014, 101, 128-140. 
Hartigan, John A and PM Hartigan, "The dip test of unimodality," The Annals of Statistics, 1985, pp. 70-84.

Heidhues, Paul and Botond Koszegi, "Behavioral Industrial Oganization," Handbook of Behavioral Economics, Elsevier, 2018.

Hossain, Tanjim and Ryo Okui, "The binarized scoring rule," The Review of Economic Studies, 2013, 80 (3), 984-1001.

Ispano, Alessandro and Peter Schwardmann, "Competition over Cursed Consumers," Working Paper, No. 7046, CESifo Group Munich 2018.

Jin, Ginger Zhe, "Competition and disclosure incentives: an empirical study of HMOs," RAND Journal of Economics, 2005, pp. 93-112.

_, Michael Luca, and Daniel J Martin, "Complex Disclosure," Working Paper, National Bureau of Economic Research 2018.

_, _, and Daniel Martin, "Is no news (perceived as) bad news? An experimental investigation of information disclosure," Working Paper, National Bureau of Economic Research 2018.

King, Ronald R and David E Wallin, "Market-induced information disclosures: An experimental markets investigation," Contemporary Accounting Research, 1991, 8 (1), $170-197$.

_ and _ , "Voluntary disclosures when seller's level of information is unknown," Journal of Accounting Research, 1991, pp. 96-108.

Krawczyk, Michał, "The search for significance: a few peculiarities in the distribution of P values in experimental psychology literature," PloS one, 2015, 10 (6), e0127872.

Lewis, Gregory, "Asymmetric information, adverse selection and online disclosure: The case of eBay motors," The American Economic Review, 2011, 101 (4), 1535-1546. 
Loewenstein, George, Cass R. Sunstein, and Russell Golman, "Disclosure: Psychology Changes Everything," Annual Review of Economics, 2014, 6 (1), 391-419.

Luca, Michael and Jonathan Smith, "Strategic disclosure: The case of business school rankings," Journal of Economic Behavior 83 Organization, 2015, 112, 17-25.

Mathios, Alan D., "The Impact of Mandatory Disclosure Laws on Product Choices: An Analysis of the Salad Dressing Market," Journal of Law and Economics, 2000, 43 (2), pp. 651-678.

Matthews, Steven and Andrew Postlewaite, "Quality Testing and Disclosure," RAND Journal of Economics, Autumn 1985, 16 (3), 328-340.

Milgrom, Paul and John Roberts, "Relying on the Information of Interested Parties," RAND Journal of Economics, Spring 1986, 17 (1), 18-32.

Milgrom, Paul R, "Good news and bad news: Representation theorems and applications," The Bell Journal of Economics, 1981, pp. 380-391.

Polinsky, A. Mitchell and Steven Shavell, "Mandatory Versus Voluntary Disclosure of Product Risks," Journal of Law, Economics, and Organization, 2010.

Roth, Alvin E and Michael W Malouf, "Game-theoretic models and the role of information in bargaining.," Psychological Review, 1979, 86 (6), 574.

Ru, Hong and Antoinette Schoar, "Do credit card companies screen for behavioral biases?," Working Paper, National Bureau of Economic Research 2016.

Serra-Garcia, Marta, Eric van Damme, and Jan Potters, "Hiding an inconvenient truth: Lies and vagueness," Games and Economic Behavior, 2011, 73 (1), 244-261.

Stanford Law Review, "Waiver of the Privilege against Self Incrimination," 1962, 14 (4), 811-826. 
Yale Law Journal, "The Privilege against Self-Incrimination: The Doctrine of Waiver," 1952, 61 (1), 105-110. 


\section{Appendix}

\section{A Proofs}

\section{A.1 Proof of proposition 3}

Prediction $1 \mathrm{a}$ and $1 \mathrm{~b}$ follow straightforwardly from proposition 1 and 2 . Next, let $E g^{\text {flex }}$ and $E g^{\text {prec }}$ denote $R$ 's expected guess under flexible and precise language

$$
\begin{aligned}
& E g^{f l e x}=\chi E g_{\chi}^{\text {flex }}+(1-\chi) E g_{1-\chi}^{\text {flex }} \\
& E g^{\text {prec }}=\chi E g_{\chi}^{\text {prec }}+(1-\chi) E g_{1-\chi}^{\text {prec }},
\end{aligned}
$$

where the subscripts $\chi$ and $1-\chi$ refer respectively to the expected guess of a naive and a sophisticated $R$. Also, let $\mu=1 / 2$ represent the prior mean.

By the law of iterated expectations, $E g_{1-\chi}^{f l e x}=E g_{1-\chi}^{\text {prec }}=\mu$. Thus, proving prediction 2a boils down to show that $E g_{\chi}^{\text {flex }}>E g_{\chi}^{\text {prec }}>\mu$. Let us denote by $g_{\chi}^{\text {flex }}(\omega)$ and $g_{\chi}^{\text {prec }}(\omega)$ the equilibrium guess of a naive $R$ when the state is $\omega$ under precise and flexible language, respectively. For any $\omega, g_{\chi}^{\text {flex }}(\omega) \geq g_{\chi}^{\text {prec }}(\omega)$, with strict inequality unless $\omega=0$ or $\omega=1$, so that $E g_{\chi}^{f l e x}>E g_{\chi}^{\text {prec }}$. Moreover, under precise language $g_{\chi}^{\text {flex }}(\omega) \geq \omega$ with strict inequality whenever $\omega \leq \omega^{*}$, so that $E g_{\chi}^{\text {prec }}>\mu$.

As for prediction $2 \mathrm{~b}, E g^{\text {flex }}$ is strictly increasing in $\chi$ since $E g_{\chi}^{\text {flex }}$ and $E g_{1-\chi}^{\text {flex }}$ are independent from $\chi$ and $E g_{\chi}^{\text {flex }}>E g_{1-\chi}^{\text {flex }} . E g^{\text {prec }}$ is strictly increasing in $\chi$ since $E g_{\chi}^{\text {prec }}>$ $E g_{1-\chi}^{\text {prec }}$ and, moreover, while $E g_{1-\chi}^{\text {prec }}$ is independent from $\chi, E g_{1-\chi}^{\text {prec }}$ is strictly increasing. Indeed

$$
E g_{\chi}^{\text {prec }}=\int_{0}^{\omega^{*}} \mu \mathrm{d} \omega+\int_{\omega^{*}}^{1} \omega \mathrm{d} \omega=\mu+\int_{0}^{\omega^{*}}(\mu-\omega) \mathrm{d} \omega,
$$

which is strictly increasing since so is $\omega^{*}$ and, as $\omega^{*}<\mu, \mu-\omega>0$ in the relevant integration range. 


\section{A.2 Proof of proposition 4}

Prediction 3a follows directly from prediction 2a. Using the notation introduced in the previous proof (section A.1), prediction $3 b$ follows from the fact that for types $\omega>\omega^{*}$, $g_{\chi}^{\text {flex }}(\omega)>g_{\chi}^{\text {prec }}(\omega)$ and $g_{1-\chi}^{\text {flex }}(\omega)=g_{1-\chi}^{\text {prec }}(\omega)$, while for types $\omega \leq \omega^{*}$ precise language is preferable if and only

$$
\chi \mu+(1-\chi) \frac{\omega^{*}}{2} \geq \chi \frac{\omega+1}{2}+(1-\chi) \omega .
$$

The inequality is violated at $\omega=\omega^{*} / 2$, verified strictly at $\omega=0$, and, since the left-hand side and right-hand side are respectively independent from $\omega$ and strictly decreasing, there is a unique $\hat{\omega} \in\left(0, \omega^{*} / 2\right)$ such that the inequality holds if and only if $\omega \leq \hat{\omega}$.

Next, if we denote the expected loss of $R$ under flexible and precise language as $E L^{\text {flex }}$ and $E L^{\text {prec }}$, respectively, and we use the subscript $\chi$ and $1-\chi$ to denote the expected loss of a naive and a sophisticated $R$, respectively, we have

$$
\begin{aligned}
& E L^{\text {prec }}=\chi \underbrace{\int_{0}^{\omega^{*}}(\mu-\omega)^{2} \mathrm{~d} \omega}_{E L_{\chi}^{\text {prec }}}+(1-\chi) \underbrace{\int_{0}^{\omega^{*}}\left(\frac{\omega^{*}}{2}-\omega\right)^{2} \mathrm{~d} \omega}_{E L_{1-\chi}^{\text {prec }}}=\frac{\chi^{2}(3+\chi)}{12(1+\chi)^{3}} \\
& E L^{\text {flex }}=\chi \underbrace{\int_{0}^{1}\left(\frac{\omega+1}{2}-\omega\right)^{2} \mathrm{~d} \omega}_{E L_{\chi}^{\text {flex }}}+(1-\chi) \underbrace{0}_{E L_{1-\chi}^{\text {flex }}}=\frac{\chi}{12} .
\end{aligned}
$$

Prediction 4a follows from $E L_{1-\chi}^{\text {prec }}>E L_{1-\chi}^{\text {flex }}=0$ and

$$
E L_{\chi}^{f l e x}>\int_{0}^{\omega^{*}}\left(\frac{\omega+1}{2}-\omega\right)^{2} \mathrm{~d} \omega>\int_{0}^{\omega^{*}}(\mu-\omega)^{2} \mathrm{~d} \omega=E L_{\chi}^{\text {prec }} .
$$

The last inequality holds because in the relevant integration range $\omega<\mu<\frac{\omega+1}{2}$. Finally prediction 4 a follows from analytical inspection, i.e. $E L^{\text {prec }}=c E L^{f l e x}$ with $c=\frac{\chi(3+\chi)}{(1+\chi)^{3}}<1$. 


\section{B Extensions}

\section{B.1 General Distribution of Naivete}

In this section we suppose the belief of a $\chi$-naive $R$ upon any given message is a mixture of the posterior of a fully sophisticated receiver (with weight $1-\chi$ ) and a fully naive receiver (with weight $\chi$ ). Besides, we assume $R$ 's type $\chi$ is drawn form a continuous distribution $h(\chi)$ with full support on $[0,1]$, mean $\lambda$ and variance $\sigma^{2}$. The binary model we use in section 2.2 hence obtains as limit and special case when $h(\chi)$ puts weight only on 0 and 1. Likewise, the model in Eyster and Rabin (2005) corresponds to a degenerate $h(\chi)$ that puts all weight on a single value of $\chi$.

One can easily verify that proposition 1 still describes $S$ 's behavior under flexible language, so that the guess of a $\chi$-naive $R$ upon message $[a, b]$ with $b \geq a$ is $g_{\chi}([a, b])=$ $\chi(a+b) / 2+(1-\chi) a$. As for $S$ 's behavior under precise language, it is as in proposition 2 except that $S$ 's disclosure cutoff now must solve

$$
\omega^{*}=\int_{0}^{1}\left(\chi \frac{1}{2}+(1-\chi) \frac{\omega^{*}}{2}\right) h(\chi) \mathrm{d} \chi
$$

The unique solution is $\omega^{*}=\frac{\lambda}{1+\lambda}$. The guess of $\chi$-naive $R$ upon nondisclosure is then $\chi \frac{1}{2}+(1-\chi) \frac{\omega^{*}}{2}$.

Thus, all results of section 2.2 generalize to this more flexible model. In particular, we formally establish an equivalent of predictions $4 \mathrm{a}$ and $4 \mathrm{~b}$.

Proposition B.1. For any distribution of naivete in the population

B.a the ex-ante expected payoff of $R$ is higher under precise language than under flexible language

B.b ex-post, the expected payoff of a $\chi$-naive $R$ is higher under precise language than under flexible language if and only if $\chi$ is above some cutoff $\chi^{*} \in(0,1)$. 
Proof. The expected loss of $R$ under flexible and precise language are now

$$
\begin{aligned}
& E L^{\text {flex }}=\int_{0}^{1} \int_{0}^{1}\left(\chi \frac{\omega+1}{2}+(1-\chi) \omega-\omega\right)^{2} \mathrm{~d} \omega h(\chi) \mathrm{d} \chi=\int_{0}^{1} \underbrace{\frac{\chi^{2}}{12}}_{E L_{\chi}^{\text {flex }}(\chi)} h(\chi) \mathrm{d} \chi \\
& E L^{\text {prec }}=\int_{0}^{1} \int_{0}^{\omega^{*}}\left(\chi \frac{1}{2}+(1-\chi) \frac{\omega^{*}}{2}-\omega\right)^{2} \mathrm{~d} \omega h(\chi) \mathrm{d} \chi=\int_{0}^{1} \underbrace{\frac{1}{12} \omega^{*}\left(\left(\omega^{*}\right)^{2}+3\left(1-\omega^{*}\right)^{2} \chi^{2}\right)}_{E L_{\chi}^{\text {prec }}(\chi)} h(\chi) \mathrm{d} \chi,
\end{aligned}
$$

where $E L_{\chi}^{f l e x}$ and $E L_{\chi}^{\text {prec }}$ denote the expected loss of type $\chi$. Prediction B.b follows from

$$
\begin{aligned}
E L_{\chi}^{\text {flex }}(0) & =0<\frac{\left(\omega^{*}\right)^{3}}{12}=E L_{\chi}^{\text {prec }}(0), \\
E L_{\chi}^{\text {flex }}(1) & =\frac{1}{12}>\frac{1}{2} \omega^{*}\left(3-6 \omega^{*}+4\left(\omega^{*}\right)^{2}\right)=E L_{\chi}^{\text {prec }}(1), \\
\frac{d E a^{f l e x}}{d \chi} & =\frac{\chi}{6}>\frac{1}{2} \omega^{*}\left(1-\omega^{*}\right)^{2} \chi=\frac{d E a^{\text {prec }}}{d \chi}
\end{aligned}
$$

As for prediction B.a, we may write

$$
\begin{aligned}
E L^{\text {prec }}-E L^{f l e x} & =\frac{1}{12} \int_{0}^{1}\left(\left(\omega^{*}\right)^{3}-\left(1-3\left(1-\omega^{*}\right)^{2} \omega^{*}\right) \chi^{2}\right) h(\chi) \mathrm{d} \chi \\
& \propto \frac{\lambda^{3}-\left(1+\lambda^{2}(3+\lambda)\right) \mathbb{E}\left[\chi^{2}\right]}{(1+\lambda)^{3}}
\end{aligned}
$$

Thus, $E L^{\text {prec }} \geq E L^{\text {flex }}$ if and only if

$$
\mathbb{E}\left[\chi^{2}\right] \leq \frac{\lambda^{3}}{1+3 \lambda^{2}+\lambda^{3}}
$$

Using $\mathbb{E}\left[\chi^{2}\right] \equiv \lambda^{2}+\sigma^{2}$, one sees that this is impossible as $\sigma^{2}>0$ and $\lambda^{2}>\frac{\lambda^{3}}{1+3 \lambda^{2}+\lambda^{3}}$.

\section{B.2 General Distribution of the State of Nature}

The equilibrium behavior described at proposition 1 and 2 naturally generalizes to any arbitrary prior distribution $f(\omega)$ which is continuous and has full-support in the interior of $[0,1]$. Let $F(\omega)$ denote its cumulative distribution and $\mu$ the prior mean. Under flexible 
language, the equilibrium is identical except that the guess of a naive $R$ upon message $[a, b]$ with $b \geq a$ is now

$$
g_{\chi}([a, b])=\mathbb{E}[\omega \mid \omega \in[a, b]]=\frac{\int_{a}^{b} \omega f(\omega) \mathrm{d} \omega}{F(b)-F(a)} .
$$

Under precise language, the equilibrium is again characterized by a disclosure cutoff $\omega^{*} \in$ $(0,1)$. For a given $\omega^{*}$, the guess of a rational and naive $R$ upon nondisclosure are now respectively $g_{1-\chi}(\emptyset)=\mathbb{E}\left[\omega \mid \omega<\omega^{*}\right]=\frac{\int_{0}^{\omega^{*}} \omega f(\omega) \mathrm{d} \omega}{F\left(\omega^{*}\right)}$ and $g_{\chi}(\emptyset)=\mu$, so that the disclosure cutoff now solves ${ }^{24}$

$$
\omega^{*}=\chi \mu+(1-\chi) \frac{\int_{0}^{\omega^{*}} \omega f(\omega) \mathrm{d} \omega}{F\left(\omega^{*}\right)} .
$$

The expected loss of $R$ under flexible and precise language are then

$$
\begin{aligned}
E L^{\text {flex }} & =\chi \underbrace{\int_{0}^{1}\left(\frac{\int_{\omega}^{1} t f(t) \mathrm{d} t}{1-F(\omega)}-\omega\right)^{2} f(\omega) \mathrm{d} \omega}_{E L_{\chi}^{\text {flex }}} \\
E L^{\text {prec }} & =\chi \underbrace{\int_{0}^{\omega^{*}}\left(\int_{0}^{1} t f(t) \mathrm{d} t-\omega\right)^{2} f(\omega) \mathrm{d} \omega}_{E L_{\chi}^{\text {prec }}}+(1-\chi) \underbrace{\int_{0}^{\omega^{*}}\left(\frac{\int_{0}^{\omega^{*}} t f(t) \mathrm{d} t}{F\left(\omega^{*}\right)}-\omega\right)^{2} f(\omega) \mathrm{d} \omega}_{E L_{1-\chi}^{\text {prec }}} .
\end{aligned}
$$

All predictions of section 2.2 other than 4 a easily extend to this setting and their proofs at section $\mathrm{A}$ intentionally rely on general arguments. ${ }^{25}$ In particular, prediction $4 \mathrm{~b}$ obtains since $E L_{1-\chi}^{\text {prec }}>E L_{1-\chi}^{\text {flex }}=0$ and

$$
E L_{\chi}^{f l e x}>\int_{0}^{\omega^{*}}(\mathbb{E}[\omega \mid \omega \in[\omega, 1]]-\omega)^{2} f(\omega) \mathrm{d} \omega>\int_{0}^{\omega^{*}}(\mu-\omega)^{2} f(\omega) \mathrm{d} \omega=E L_{\chi}^{\text {prec }},
$$

where again the last inequality holds since in the relevant integration range $\omega<\mu<$ $\mathbb{E}[\omega \mid \omega \in[\omega, 1]]$.

\footnotetext{
${ }^{24}$ The solution is not necessarily unique. A sufficient condition for this to be the case is that $f(\omega)$ is log-concave.

${ }^{25}$ For the sake of precision, prediction $2 \mathrm{~b}$ now requires equation B.1 to have a unique solution and prediction $3 \mathrm{~b}$ requires the equivalent of inequality A.1, i.e.

$$
\chi \mu+(1-\chi) \mathbb{E}\left[\omega \mid \omega<\omega^{*}\right] \geq \chi \mathbb{E}\left[\omega \mid \omega \geq \omega^{*}\right]+(1-\chi) \omega
$$

to hold with equality for a unique $\omega$. Log-concavity of $f(\omega)$ guarantees both.
} 
As for prediction 4a, we investigate it by simulation. In detail, we use as family of priors the beta distribution, which is defined on $[0,1]$ and can take a wide range of shapes (u-shaped, hill-shaped, increasing, decreasing) depending on its parameters $\alpha>0$ and $\beta>0 .{ }^{26}$ We numerically solve the model for different values of $\alpha$ and $\beta$, each ranging from $1 / 10$ to 10 , and of $\chi$, ranging from $1 / 20$ to $19 / 20$, and check whether $E L^{\text {flex }}-E L^{\text {prec }}>0 .{ }^{27}$

The inequality is verified for 2226 out of 2250 parameter combinations. The 24 counterexamples all obtain when $\alpha \geq 3$ and $\beta=1 / 10$, i.e. when the prior mean $\left(\frac{\alpha}{\alpha+\beta}\right)$ is very large and the probability mass concentrated around $1 .{ }^{28}$ The sender's ability to make upwardly vague claims under flexible language is then somehow limited by construction, while the set of types who disclose under precise language can be very small. This explains why information transmission may eventually be higher under flexible language. This occurs for intermediate levels of naivete in the population (in all counterexamples $\chi \in[13 / 20,17 / 20]$ ), so that the disclosure cutoff under precise language remains large while at the same time the welfare of sophisticates has non-negligible weight in average receiver's welfare. Notice, however, that in all counterexamples the percentage reduction in information transmission that imposing precise language entails is small, i.e. $\frac{E L^{f l e x}-E L^{p r e c}}{E L^{f l e x}}<-4 \%$, while in "regular"' instances the correspondent percentage gain is typically larger (larger than $20 \%$ in $95 \%$ of the regular instances, and as high as $99 \%) .{ }^{29}$

${ }^{26}$ The density of a beta distribution with shape parameters $\alpha>0$ and $\beta>0$ is

$$
f(\omega)=\frac{\omega^{\alpha-1}(1-\omega)^{\beta-1}}{\int_{0}^{1} t^{\alpha-1}(1-t)^{\beta-1} \mathrm{~d} t} .
$$

${ }^{27}$ When $\alpha<1$ or $\beta<1$, equation (B.1) can in principle have multiple solutions. Since $E L^{\text {prec }}$ is increasing in the disclosure cutoff, we programmed both a more stringent test which uses the largest solution and a weaker test which uses the smallest one. This precaution proved unnecessary as in all instances $\omega^{*}$ turned out to be unique.

${ }^{28}$ When $\alpha>1$ and $\beta<1$, the density of the beta distribution is hyperbolic increasing with a vertical asymptote at 1 and, as $\alpha / \beta$ increases, the distribution gets steeper at high values of $\omega$ and flatter elsewhere.

${ }^{29}$ Interestingly, the highest percentage gains from imposing precise language obtain for the same distributions that generate counterexamples but for different fractions of naives, namely, for $\chi$ very small. This suggests that imposing precise language might still be on average preferable even for these prior distributions if the regulator faces some uncertainty about the level of sophistication in the population. 


\section{Evolution of play}

After each round, each subject receives feedback about the sender's type and the receiver's guess in her pair. Tables 2 and 3 summarize how sender behavior evolves over rounds in FLEXIBLE and PRECISE, respectively. We split the total number of rounds in three phases of five rounds each, i.e phase 1 (rounds 1 to 5), phase 2 (rounds 6 to 10) and phase 3 (rounds 11 to 15). In Flexible, the most frequent messages of types 3, 4, and 5 coincide with the theoretical predictions in all phases. Types 1 and 2 in rounds 1-5 use most frequently nondisclosure rather than their theoretically predicted message, i.e. respectively $\{1,2,3,4,5\}$ and $\{2,3,4,5\}$. However, over time their behavior get closer to the theoretical predictions. In particular, in rounds 6-10 and 11-15 types 2 most frequently send the predicted message. Likewise, in rounds 11-15, the predicted message of type 1 is almost as frequent as nondisclosure (14 subjects of type 1 do not disclose, 12 subjects send $\{1,2,3,4,5\}$ and 2 subjects send $\{1,2,3,4\})$.

In PRECISE, we observe that over time disclosure rates generally increase for high types and decrease for low types. The sharp increase in the disclosure rate of types 2 is likely to reflect a shift in the disclosure threshold, i.e. a strategic response to the increase in receiver skepticism documented below. Instead, the increase in the disclosure rate of types 5 is likely to be the result of learning, i.e. a reduction in noisy behavior.

Table 2 Modal sender messages over time in FLEXIBLE

\begin{tabular}{|l|c|c|c|c|c|c|}
\cline { 2 - 7 } \multicolumn{1}{c|}{} & type=0 & type=1 & type=2 & type=3 & type=4 & type=5 \\
\hline rounds 1-5 & nondisclosure & nondisclosure & nondisclosure & $\{3,4,5\}$ & $\{4,5\}$ & $\{5\}$ \\
\hline rounds 6-10 & nondisclosure & nondisclosure & $\{2,3,4,5\}$ & $\{3,4,5\}$ & $\{4,5\}$ & $\{5\}$ \\
\hline rounds 11-15 & nondisclosure & nondisclosure & $\{2,3,4,5\}$ & $\{3,4,5\}$ & $\{4,5\}$ & $\{5\}$ \\
\hline
\end{tabular}

Table 3 Disclosure rates over time in PRECISE

\begin{tabular}{|l|c|c|c|c|c|c|}
\cline { 2 - 7 } \multicolumn{1}{c|}{} & type=0 & type=1 & type=2 & type=3 & type=4 & type=5 \\
\hline rounds 1-5 & $6.3 \%$ & $10 \%$ & $20.6 \%$ & $71.1 \%$ & $83.8 \%$ & $70.8 \%$ \\
\hline rounds 6-10 & $3.5 \%$ & $3 \%$ & $38.9 \%$ & $92.1 \%$ & $93.1 \%$ & $93.3 \%$ \\
\hline rounds 11-15 & $5 \%$ & $3 \%$ & $66.7 \%$ & $85.2 \%$ & $93 \%$ & $92.9 \%$ \\
\hline
\end{tabular}


On the receiver side, the average normalized guess decreases over time, suggesting that receivers become more skeptical (see also prediction 2b). In FLEXIBLE, the average normalized guess is $32 \%$ in rounds $1-5,23.1 \%$ in rounds $6-10$, and $19 \%$ in rounds $11-15$. In PRECISE, it decreases from $38.2 \%$, to $33.7 \%$ in rounds $6-10$, and to $27 \%$ in rounds $11-15$. The regressions in Table 1 show that there is also a negative time trend in receiver mistakes. However, receivers keep significantly overestimating sender types in all phases (two-tailed t-tests with clustering on subject and on pair level, for all phases $p$-value $<0.001$ ).

Columns (1) to (4) in Table 4 document no differential treatment effect on information transmission across phases. In column (5), we observe that the treatment effect for sophisticated receivers significantly increases in the direction predicted by theory in rounds 11-15. Column (6) confirms the estimation from Table 1 and shows no significant variation over time. However, we acknowledge that the analysis of interactions between time effects and treatment may suffer from a lack of power.

\section{Alternative classification of naives and sophisticates}

This appendix demonstrates the robustness of results in columns 3 through 6 of Table 1 by repeating the analysis using different classifications of sophistication and naivete. In columns 1 and 2 of Table 5, receivers are classified as sophisticated if they are "rarely naive", i.e. if they make the fully naive choice in less than 30 percent of the rounds in which they face either vague disclosure or nondisclosure. In columns 3 and 4 of Table 5 , receivers are classified as sophisticated if they are "never naive", i.e. if they never make a fully naive choice in the rounds in which they face either vague disclosure or nondisclosure. In columns 5 and 6 of Table 5 , we use a measure that is exogenous to receiver's choices in the experiment for the classification: we classify receivers with a high school math grade (Abitur) of 1 or 2 as sophisticated and receivers with a math grade of 3, 4, 5 or 6 as naives. This classification is equivalent to a median split.

When we use the "rarely naive" criterion, we find that naives make significantly smaller 


\begin{tabular}{|c|c|c|c|c|c|c|}
\hline Dep. variable: & $\begin{array}{c}(1) \\
\text { Mistake } \\
\end{array}$ & $\begin{array}{c}(2) \\
\text { Mistake } \\
\end{array}$ & $\begin{array}{c}(3) \\
\text { Mistake } \\
\end{array}$ & $\begin{array}{c}(4) \\
\text { Mistake } \\
\end{array}$ & $\begin{array}{c}(5) \\
\text { Mistake } \\
\end{array}$ & $\begin{array}{c}(6) \\
\text { Mistake } \\
\end{array}$ \\
\hline Precise (d) & $\begin{array}{l}-0.115 \\
(0.0911)\end{array}$ & $\begin{array}{l}-0.196^{*} \\
(0.101)\end{array}$ & $\begin{array}{c}-0.227^{*} \\
(0.126)\end{array}$ & $\begin{array}{c}-0.316^{* * *} \\
(0.0993)\end{array}$ & $\begin{array}{r}-0.0267 \\
(0.110)\end{array}$ & $\begin{array}{l}-0.0404 \\
(0.108)\end{array}$ \\
\hline Rounds 1-5 (d) & $\begin{array}{l}0 \\
(.)\end{array}$ & $\begin{array}{c}0 \\
(.)\end{array}$ & $\begin{array}{l}0 \\
(.)\end{array}$ & $\begin{array}{l}0 \\
(.)\end{array}$ & $\begin{array}{c}0 \\
(.)\end{array}$ & $\begin{array}{c}0 \\
(.)\end{array}$ \\
\hline Rounds 6-10 (d) & $\begin{array}{c}-0.257^{* * *} \\
(0.0692)\end{array}$ & $\begin{array}{l}-0.188^{* *} \\
(0.0757)\end{array}$ & $\begin{array}{c}-0.302^{* * *} \\
(0.107)\end{array}$ & $\begin{array}{c}-0.314^{* * *} \\
(0.0990)\end{array}$ & $\begin{array}{c}-0.284^{* * *} \\
(0.0768)\end{array}$ & $\begin{array}{l}-0.148 \\
(0.0919)\end{array}$ \\
\hline Rounds 11-15 (d) & $\begin{array}{c}-0.349^{* * *} \\
(0.0785)\end{array}$ & $\begin{array}{c}-0.276^{* * *} \\
(0.0922)\end{array}$ & $\begin{array}{c}-0.328^{* *} \\
(0.130)\end{array}$ & $\begin{array}{c}-0.434^{* * *} \\
(0.142)\end{array}$ & $\begin{array}{c}-0.380^{* * *} \\
(0.0841)\end{array}$ & $\begin{array}{l}-0.128 \\
(0.109)\end{array}$ \\
\hline Precise $\times$ Rounds 1-5 (d) & $\begin{array}{c}0 \\
(.)\end{array}$ & $\begin{array}{c}0 \\
(.)\end{array}$ & $\begin{array}{c}0 \\
(.)\end{array}$ & $\begin{array}{c}0 \\
(.)\end{array}$ & $\begin{array}{c}0 \\
(.)\end{array}$ & $\begin{array}{c}0 \\
(.)\end{array}$ \\
\hline Precise $\times$ Rounds 6-10 (d) & $\begin{array}{l}0.0694 \\
(0.107)\end{array}$ & $\begin{array}{c}0.0959 \\
(0.0989)\end{array}$ & $\begin{array}{l}0.0247 \\
(0.160)\end{array}$ & $\begin{array}{c}0.113 \\
(0.134)\end{array}$ & $\begin{array}{c}0.209 \\
(0.132)\end{array}$ & $\begin{array}{c}0.177 \\
(0.113)\end{array}$ \\
\hline Precise $\times$ Rounds $11-15(\mathrm{~d})$ & $\begin{array}{l}0.0911 \\
(0.124)\end{array}$ & $\begin{array}{l}0.0641 \\
(0.111)\end{array}$ & $\begin{array}{l}-0.103 \\
(0.186)\end{array}$ & $\begin{array}{c}0.148 \\
(0.173)\end{array}$ & $\begin{array}{c}0.292^{* *} \\
(0.141)\end{array}$ & $\begin{array}{l}0.0423 \\
(0.118)\end{array}$ \\
\hline Constant & $\begin{array}{c}1.624^{* * *} \\
(0.102)\end{array}$ & $\begin{array}{c}1.757^{* * *} \\
(0.119)\end{array}$ & $\begin{array}{c}2.120^{* * *} \\
(0.165)\end{array}$ & $\begin{array}{c}2.319^{* * *} \\
(0.156)\end{array}$ & $\begin{array}{c}1.270^{* * *} \\
(0.113)\end{array}$ & $\begin{array}{c}1.299^{* * *} \\
(0.133)\end{array}$ \\
\hline Type dummies & Yes & Yes & Yes & Yes & Yes & Yes \\
\hline Incl. sender choices & All & $\begin{array}{l}\text { Theory- } \\
\text { conforming }\end{array}$ & All & $\begin{array}{l}\text { Theory- } \\
\text { conforming }\end{array}$ & All & $\begin{array}{l}\text { Theory- } \\
\text { conforming }\end{array}$ \\
\hline Incl. receivers & All & All & Naives & Naives & Soph. & Soph. \\
\hline$R^{2}$ & 0.173 & 0.457 & 0.338 & 0.608 & 0.136 & 0.454 \\
\hline Observations & 1185 & 828 & 510 & 360 & 675 & 468 \\
\hline
\end{tabular}

Table 4 OLS regressions of the treatment effect on receivers' absolute mistakes over time; robust standard errors clustered at the subject level in parentheses; ${ }^{*} p<0.10,{ }^{* *} p<0.05,{ }^{* * *} p<0.01$.

mistakes under precise language and that sophisticates make insignificantly larger mistakes under precise language. This mimics our findings when we use the "hardly ever naive" criterion in the main text. When we use the "never naive" criterion (columns 3 and 4), naives make insignificantly smaller mistakes under precise language, while sophisticates make significantly larger mistakes. The "never naive" criterion results in a more selective pool of sophisticates who are hurt by moving from flexible to precise language. When we classify receivers based on their high school math grade (columns 5 and 6), we find that naives do significantly worse and that sophisticates do insignificantly better under precise language.

The above criteria, except for the math grade, are based on the incidence of naive choices and therefore pool all other choices under the label of sophisticated behavior. 
Alternatively, we may call a receiver sophisticated if her choices line up well with empirical best response behavior. Table 5 uses three notions of empirical best response behavior to classify receivers. Consider the criterion "best response 1". As in section C, we divide our experiment into phase 1 (rounds 1 to 5 ), phase 2 (rounds 6 to 10) and phase 3 (rounds 11 to 15). For each phase and each possible message, including nondisclosure, we calculate the average type that actually sent this message. The use of phases allows us to arrive at a more precise measure of average behavior. We call a receiver's guess a noisy empirical best response if it lies less than 0.5 above and less than 0.5 below the average sender type conditional on a given message. The criterion "best response 1" then classifies a receiver as sophisticated if her guess is a noisy best response in more than 75 percent of rounds that featured either vague disclosure or nondisclosure. The criterion "best response 2" is laxer and classifies an individual as sophisticated if her guess is a noisy best response in more than 50 percent of rounds that featured either vague disclosure or nondisclosure. The criterion "best response 3" is defined like "best response 1" except that is allows for a 1-unit deviation from the true average type in defining the empirical best response.

In Table 5, columns 1 and 2 feature the criterion "best response 1" and columns 3 and 4 the same criterion, but only theory-conforming sender behavior. Columns 5 and 6 feature best response 2, whereas columns 7 and 8 feature best response 3 . In all cases, naives are found to make significantly smaller mistakes under precise language, while there is no treatment effect on sophisticates. A direct implication of our model's prediction that naives are better off and sophisticates are worse off under precise language is that the negative treatment effect of imposing precise language on receiver mistakes is larger for naives, i.e. that there is a significant interaction effect between treatment and sophistication. Table 6 confirms that the data bears out this prediction for all criteria we have introduced above. 


\begin{tabular}{|c|c|c|c|c|c|c|}
\hline & $\begin{array}{c}(1) \\
\text { Mistake }\end{array}$ & $\begin{array}{c}(2) \\
\text { Mistake }\end{array}$ & $\begin{array}{c}(3) \\
\text { Mistake }\end{array}$ & $\begin{array}{c}(4) \\
\text { Mistake }\end{array}$ & $\begin{array}{c}(5) \\
\text { Mistake }\end{array}$ & $\begin{array}{c}(6) \\
\text { Mistake }\end{array}$ \\
\hline Precise (d) & $\begin{array}{l}-0.186^{*} \\
(0.0971)\end{array}$ & $\begin{array}{c}0.0294 \\
(0.0762)\end{array}$ & $\begin{array}{l}-0.0856 \\
(0.0853)\end{array}$ & $\begin{array}{c}0.188^{* * *} * \\
(0.0633)\end{array}$ & $\begin{array}{c}-0.343^{* * *} \\
(0.0928)\end{array}$ & $\begin{array}{c}0.0265 \\
(0.0822)\end{array}$ \\
\hline Round & $\begin{array}{l}-0.0202 \\
(0.0138)\end{array}$ & $\begin{array}{c}-0.0319 * * * \\
(0.00607)\end{array}$ & $\begin{array}{c}-0.0333^{* * *} \\
(0.00755)\end{array}$ & $\begin{array}{c}-0.0207 * * \\
(0.00852)\end{array}$ & $\begin{array}{c}-0.0491 * * * \\
(0.0106)\end{array}$ & $\begin{array}{c}-0.0250 * * * \\
(0.00653)\end{array}$ \\
\hline Constant & $\begin{array}{c}2.189 * * * \\
(0.250)\end{array}$ & $\begin{array}{c}1.445^{* * *} \\
(0.112)\end{array}$ & $\begin{array}{c}1.977^{* * *} \\
(0.136)\end{array}$ & $\begin{array}{c}1.008^{* * *} \\
(0.0961)\end{array}$ & $\begin{array}{c}2.411^{* * *} \\
(0.142)\end{array}$ & $\begin{array}{c}1.432^{* * *} \\
(0.112)\end{array}$ \\
\hline Type dummies & Yes & Yes & Yes & Yes & Yes & Yes \\
\hline Incl. receivers & Naives & Soph. & Naives & Soph. & Naives & Soph. \\
\hline Criterion & \multicolumn{2}{|c|}{ Rarely naive } & \multicolumn{2}{|c|}{ Never naive } & \multicolumn{2}{|c|}{ Math grade } \\
\hline$R^{2}$ & 0.361 & 0.138 & 0.265 & 0.116 & 0.375 & 0.130 \\
\hline Observations & 300 & 885 & 750 & 435 & 330 & 855 \\
\hline
\end{tabular}

Table 5 OLS regressions of the treatment effect on receivers' absolute mistakes; robust standard errors clustered at the subject level in parentheses; ${ }^{*} p<0.10,{ }^{* *} p<0.05,{ }^{* * *} p<0.01$.

\begin{tabular}{|c|c|c|c|c|c|c|c|c|}
\hline & $\begin{array}{c}(1) \\
\text { Mistake }\end{array}$ & $\begin{array}{c}(2) \\
\text { Mistake } \\
\end{array}$ & $\begin{array}{c}(3) \\
\text { Mistake } \\
\end{array}$ & $\begin{array}{c}(4) \\
\text { Mistake } \\
\end{array}$ & $\begin{array}{c}5) \\
\text { Mistake } \\
\end{array}$ & $\begin{array}{c}6) \\
\text { Mistake } \\
\end{array}$ & $\begin{array}{c}(7) \\
\text { Mistake } \\
\end{array}$ & $\begin{array}{c}(8) \\
\text { Mistake } \\
\end{array}$ \\
\hline Precise (d) & $\begin{array}{c}-0.257^{* * *} \\
(0.0810)\end{array}$ & $\begin{array}{c}0.125 \\
(0.0814)\end{array}$ & $\begin{array}{c}-0.359^{* * *} \\
(0.0873)\end{array}$ & $\begin{array}{c}0.0297 \\
(0.0482)\end{array}$ & $\begin{array}{c}-0.311^{* * *} \\
(0.0811)\end{array}$ & $\begin{array}{l}-0.0775 \\
(0.0746)\end{array}$ & $\begin{array}{c}-0.257^{* * *} \\
(0.0932)\end{array}$ & $\begin{array}{l}0.00789 \\
(0.0439)\end{array}$ \\
\hline Round & $\begin{array}{c}-0.0280^{* * *} \\
(0.00774)\end{array}$ & $\begin{array}{c}-0.0339^{* * *} \\
(0.00852)\end{array}$ & $\begin{array}{c}-0.0198^{* * *} \\
(0.00670)\end{array}$ & $\begin{array}{c}-0.0206^{* * *} \\
(0.00572)\end{array}$ & $\begin{array}{l}-0.0178 \\
(0.0105)\end{array}$ & $\begin{array}{c}-0.0361^{* * *} \\
(0.00634)\end{array}$ & $\begin{array}{c}-0.0219^{* * *} \\
(0.00762)\end{array}$ & $\begin{array}{c}-0.0185^{* * *} \\
(0.00439)\end{array}$ \\
\hline Constant & $\begin{array}{c}2.050^{* * *} \\
(0.132)\end{array}$ & $\begin{array}{c}1.220^{* * *} \\
(0.115)\end{array}$ & $\begin{array}{c}2.179^{* * *} \\
(0.144)\end{array}$ & $\begin{array}{c}1.219^{* * *} \\
(0.111)\end{array}$ & $\begin{array}{c}2.240^{* * *} \\
(0.174)\end{array}$ & $\begin{array}{c}1.458^{* * *} \\
(0.110)\end{array}$ & $\begin{array}{c}2.286^{* * *} \\
(0.164)\end{array}$ & $\begin{array}{c}1.238^{* * *} \\
(0.0975)\end{array}$ \\
\hline Type dummies & Yes & Yes & Yes & Yes & Yes & Yes & Yes & Yes \\
\hline Incl. receivers & Naives & Soph. & Naives & Soph. & Naives & Soph. & Naives & Soph. \\
\hline Criterion & \multicolumn{2}{|c|}{ Best response 1} & \multicolumn{2}{|c|}{ Best response 1} & \multicolumn{2}{|c|}{ Best response 2} & \multicolumn{2}{|c|}{ Best response 3} \\
\hline Sender choices & \multicolumn{2}{|c|}{ All } & \multicolumn{2}{|c|}{$\begin{array}{l}\text { Theory- } \\
\text { conforming }\end{array}$} & \multicolumn{2}{|c|}{ All } & \multicolumn{2}{|c|}{ All } \\
\hline$R^{2}$ & 0.264 & 0.134 & 0.532 & 0.569 & 0.359 & 0.124 & 0.550 & 0.592 \\
\hline Observations & 720 & 465 & 519 & 309 & 420 & 765 & 410 & 418 \\
\hline
\end{tabular}

Table 6 OLS regressions of the treatment effect on receivers' absolute mistakes; robust standard errors clustered at the subject level in parentheses; ${ }^{*} p<0.10,{ }^{* *} p<0.05,{ }^{* * *} p<0.01$. 


\begin{tabular}{|c|c|c|c|c|c|c|c|}
\hline & $\begin{array}{c}(1) \\
\text { Mistake }\end{array}$ & $\begin{array}{c}(2) \\
\text { Mistake }\end{array}$ & $\begin{array}{c}(3) \\
\text { Mistake }\end{array}$ & $\begin{array}{c}(4) \\
\text { Mistake }\end{array}$ & $\begin{array}{c}(5) \\
\text { Mistake }\end{array}$ & $\begin{array}{c}(6) \\
\text { Mistake }\end{array}$ & $\begin{array}{c}(7) \\
\text { Mistake }\end{array}$ \\
\hline Precise (d) & $\begin{array}{c}-0.255^{* * *} \\
(0.0785)\end{array}$ & $\begin{array}{c}0.213 \\
(0.157)\end{array}$ & $\begin{array}{c}-0.209^{* *} \\
(0.102)\end{array}$ & $\begin{array}{l}-0.0824 \\
(0.0852)\end{array}$ & $\begin{array}{c}-0.256^{* * *} \\
(0.0814)\end{array}$ & $\begin{array}{c}-0.326^{* * *} \\
(0.0915)\end{array}$ & $\begin{array}{l}-0.161^{*} \\
(0.0891)\end{array}$ \\
\hline Round & $\begin{array}{c}-0.0299^{* * *} \\
(0.00583)\end{array}$ & $\begin{array}{c}-0.0299^{* * *} \\
(0.00582)\end{array}$ & $\begin{array}{c}-0.0299^{* * *} \\
(0.00582)\end{array}$ & $\begin{array}{c}-0.0299^{* * *} \\
(0.00582)\end{array}$ & $\begin{array}{c}-0.0299 * * * \\
(0.00583)\end{array}$ & $\begin{array}{c}-0.0299 * * * \\
(0.00583)\end{array}$ & $\begin{array}{c}-0.0299 * * * \\
(0.00583)\end{array}$ \\
\hline Hardly ever naive (d) & $\begin{array}{c}-0.471^{* * *} \\
(0.0684)\end{array}$ & & & & & & \\
\hline Precise $x$ Hardly naive (d) & $\begin{array}{c}0.384^{* * *} \\
(0.111)\end{array}$ & & & & & & \\
\hline Math grade & & $\begin{array}{c}0.100^{*} \\
(0.0515)\end{array}$ & & & & & \\
\hline Precise $x$ Math grade $(d)$ & & $\begin{array}{c}-0.132^{* *} \\
(0.0615)\end{array}$ & & & & & \\
\hline Rarely naive (d) & & & $\begin{array}{c}-0.366^{* * *} \\
(0.0774)\end{array}$ & & & & \\
\hline Precise $x$ Rarely naive $(\mathrm{d})$ & & & $\begin{array}{l}0.229^{*} \\
(0.127)\end{array}$ & & & & \\
\hline Never naive $(d)$ & & & & $\begin{array}{c}-0.419^{* * *} \\
(0.0666)\end{array}$ & & & \\
\hline Precise $\mathrm{x}$ Never naive $(\mathrm{d})$ & & & & $\begin{array}{c}0.247^{* *} \\
(0.107)\end{array}$ & & & \\
\hline Best response $1(\mathrm{~d})$ & & & & & $\begin{array}{c}-0.448^{* * *} \\
(0.0732)\end{array}$ & & \\
\hline Precise $\mathrm{x}$ Best resp. 1 (d) & & & & & $\begin{array}{c}0.345^{* * *} \\
(0.111)\end{array}$ & & \\
\hline Best response $2(\mathrm{~d})$ & & & & & & $\begin{array}{c}-0.398^{* * *} \\
(0.0830)\end{array}$ & \\
\hline Precise $\mathrm{x}$ Best resp. 2 (d) & & & & & & $\begin{array}{l}0.229^{*} \\
(0.118)\end{array}$ & \\
\hline Best response $3(\mathrm{~d})$ & & & & & & & $\begin{array}{c}-0.448^{* * *} \\
(0.0733)\end{array}$ \\
\hline Precise $\mathrm{x}$ Best resp. 3 (d) & & & & & & & $\begin{array}{l}0.205^{*} \\
(0.108)\end{array}$ \\
\hline Constant & $\begin{array}{c}1.907^{* * *} \\
(0.0978)\end{array}$ & $\begin{array}{c}1.450^{* * *} \\
(0.148)\end{array}$ & $\begin{array}{c}1.908^{* * *} \\
(0.100)\end{array}$ & $\begin{array}{c}1.765^{* * *} \\
(0.105)\end{array}$ & $\begin{array}{c}1.888^{* * *} \\
(0.105)\end{array}$ & $\begin{array}{c}1.995^{* * *} \\
(0.102)\end{array}$ & $\begin{array}{c}1.892^{* * *} \\
(0.106)\end{array}$ \\
\hline$R^{2}$ & 0.208 & 0.177 & 0.192 & 0.197 & 0.205 & 0.189 & 0.213 \\
\hline Observations & 1185 & 1185 & 1185 & 1185 & 1185 & 1185 & 1185 \\
\hline
\end{tabular}

Table 7 OLS regressions of the treatment effect on receivers' absolute mistakes; robust standard errors clustered at the subject level in parentheses; ${ }^{*} p<0.10,{ }^{* *} p<0.05,{ }^{* * *} p<0.01$. 


\section{E Decision Screens}

Figure 4 shows an example sender decision screen in PRECISE. Here, the senders were provided with the two options in random order.

Figure 5 shows the decision screen in FLEXIBLE. The sender could freely specify the interval to send by clicking on and herewith selecting the respective types to be included. A preview window showed how the message would appear on the receiver's screen.

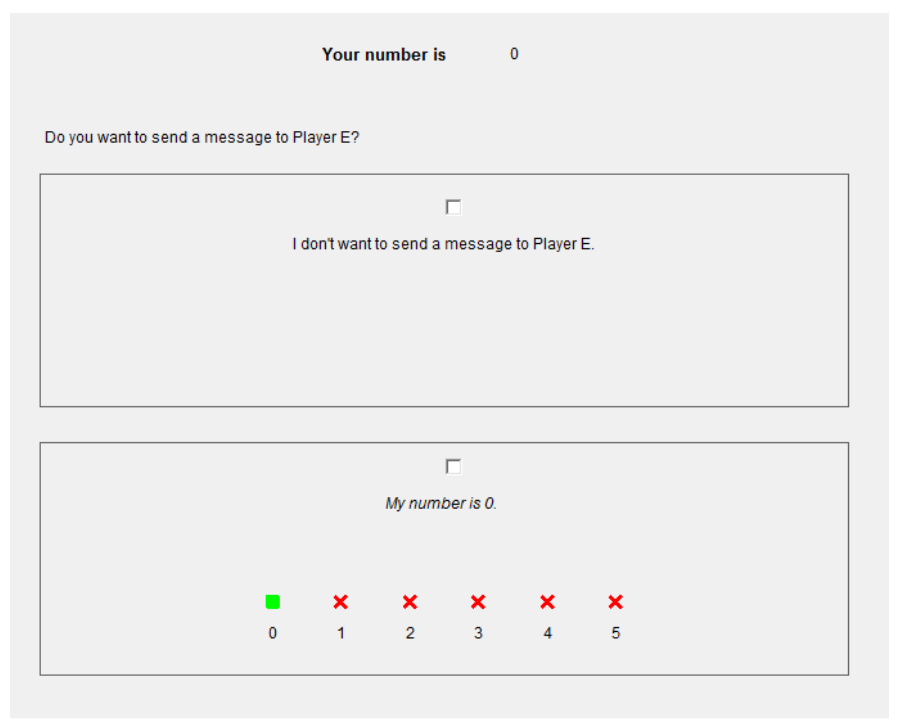

Figure 4 Sender's decision screen in PRECISE

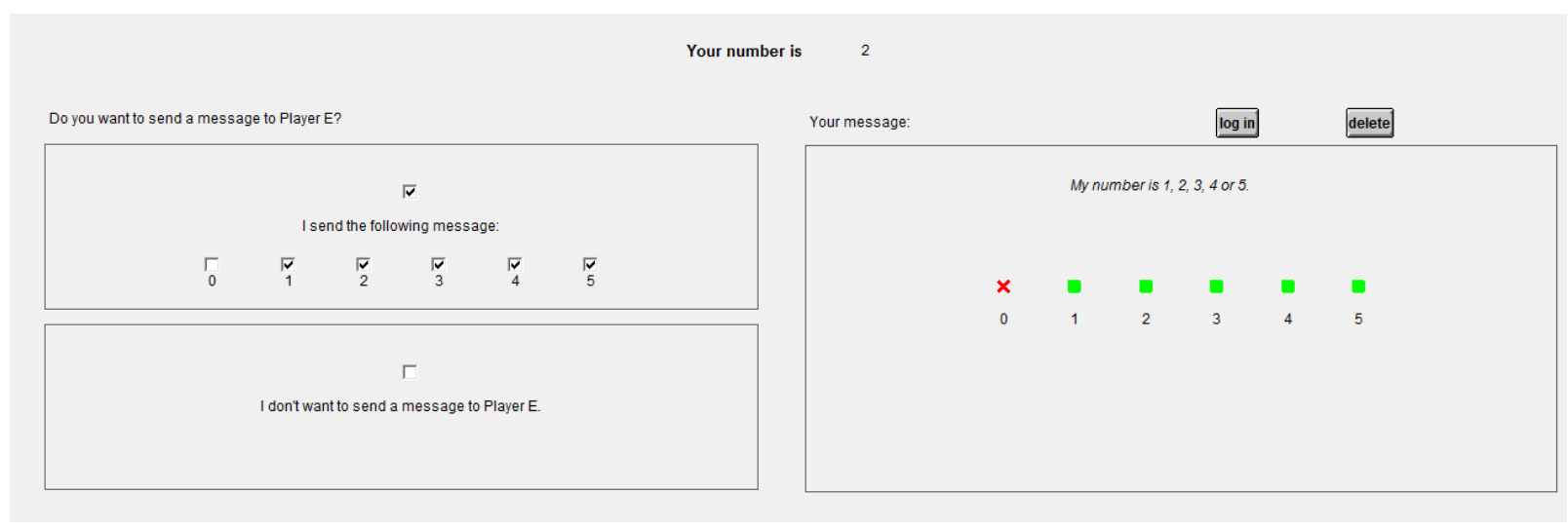

Figure 5 Sender's decision screen in FLEXIBLE 


\section{F Instructions}

\section{F.1 Flexible treatment}

This experiment is composed of 15 rounds. At the beginning of this experiment, it will be determined randomly whether you are player $\mathbf{S}$ or player E. You will keep this role in all 15 rounds. In each round you play a game with a randomly chosen participant in the opposite role. It is very unlikely, that you are paired up with the same participant in two consecutive rounds.

\section{The Game}

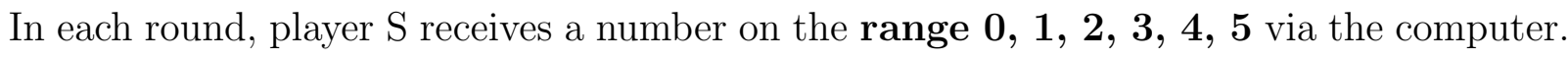
All the numbers are equally likely. Player E does not see which number player S receives. However, player S can send a message regarding his or her number to player E. Player E must guess the number of player S. At the end of each round both players are informed about the number of player $\mathrm{S}$ and the guess of player $\mathrm{E}$.

\section{Decision of player $\mathrm{S}$}

After receiving the number, player S can decide about whether or not he or she would like to send a message to the recipient. Player S can decide which message he or she would like to send. In doing so, three rules must be complied with:

\section{The sent message must contain the true number of the sender}

Example: If the sender receives number 3, he can only send messages that contain the number 3 .

2. The sent message must not contain gaps.

Example: The sender with number 3 must not send the numbers 2, 3, 5 as possible numbers because the 4 is missing in this row.

3. The send message may contain maximum five numbers. 


\begin{tabular}{|c|c|}
\hline Probability & Payoff \\
\hline PP\% & 8 Euro \\
\hline$(100-\mathrm{PP}) \%$ & 1 Euro \\
\hline
\end{tabular}

Example: The sender with the number 3 may only send 5 of is possible numbers in total. The sender may not send all six numbers (i.e. $0,1,2,3,4,5$ ).

When player $\mathrm{S}$ has received, for example, the number 3, he or she can send a message that contains the true number and no gaps or send no message at all. This, for example, applies to the message "My number is 3.". Graphically, the message "My number is 3" will be depicted by a green box above number 3 and red crosses above $0,1,2,4$ and 5 :

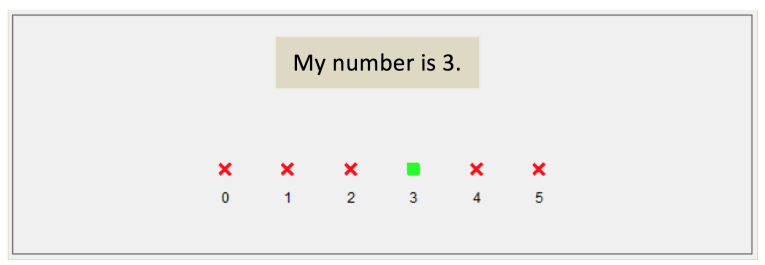

\section{Decision of player $\mathrm{E}$}

Player E either sees the message sent by player $\mathrm{S}$ or he or she will see the note "Player $\mathrm{S}$ has not sent you a message." if player S has decided not to send a message. Then, player E must enter his or her guess about the actual number of player S. Here, every number can be entered in 0.5-intervals $(0,0.5,1,1.5,2,2.5,3,3.5,4,4.5,5)$.

\section{Payoff}

The payment is determined by the following rules: The higher the guess of player E, the higher the payment of player S. And the closer the guess of player $\mathrm{E}$ is to the true number of player $\mathrm{S}$, the higher the payment of player E.

Hereafter, the mechanism which determines the payment is explained in detail.

In each round you can earn between 0 and 100 probability points (PP). The more probability points you earn, the higher the probability that you win the subsequent lottery:

If you gain 0 probability points you receive with certainty (with 100\%) 1 Euro. If you gain 100 probability points you receive with certainty (with 100\%) 8 Euro. If you gain 
e.g. 70 probability points, you receive, with the probability of $70 \%, 8$ Euro and, with the probability of $30 \% 1$ Euro. The more probability points you gain, the more probable it is that you receive 8 instead of 1 .

\section{Thus, you should try to gain as many probability points as possible.}

The amount of your probability points in one round depends on both the number of player S and the guess of player E. The payoff table, which you can find at your spot, makes this clear. If player S e.g. receives the number 3 and player E guesses number 4.5, player E gains 79 probability points and player S 96 probability points. But, if player E guesses that the number of Player $\mathrm{S}$ is 1, player E gains 69 probability points and player S only 19 probability points.

Only one of the 15 rounds is chosen randomly and then is actually relevant to the payoff. Your probability points in this round determine the lottery that is played by the computer at the end of the experiment. Since you do not know, which of the 15 rounds is relevant to the payoff you should think carefully about your decisions in each round.

\section{Summary}

- Player S receives a random number that is unknown to player E.

- Player S decides whether or not to send a message to player E regarding the number. The message must contain the number of player $\mathrm{S}$.

- What the message contains is determined by player S.

- Player E must guess the number of player S.

- The higher player E guesses the number of player S, the higher the chances of achieving a higher profit for player S.

- The more accurate the guess of player $\mathrm{E}$ for the number is, the higher the chances of profits for player E. 


\section{F.2 Precise treatment}

This experiment is composed of 15 rounds. At the beginning of this experiment, it will be determined randomly whether you are player $\mathbf{S}$ or player E. You will keep this role in all 15 rounds. In each round you play a game with a randomly chosen participant in the opposite role. It is very unlikely, that you are paired up with the same participant in two consecutive rounds.

\section{The Game}

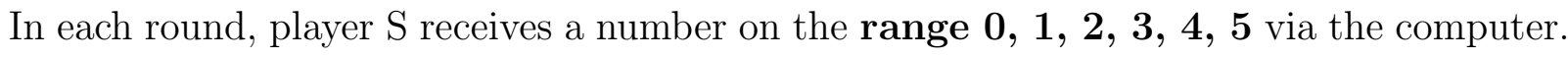
All the numbers are equally probable. Player E does not see which number player S receives. However, player S can send a message regarding his or her number to player E. Player E must guess the number of player S.

At the end of each round both players are informed about the number of player $\mathrm{S}$ and the guess of player E.

\section{Decision of player $\mathrm{S}$}

After receiving the number, player $\mathrm{S}$ can decide about whether or not he or she would like to send a message to the recipient. If player $\mathrm{S}$ does send a message, player $\mathrm{E}$ will be informed about the number. If player $\mathrm{S}$ does not send a message, player $\mathrm{E}$ will not be informed about the number.

When player $\mathrm{S}$ has received e.g. the number 3 , he or she can send a message that contains the true number or send no message at all. This, for example, applies to the message "My number is 3". Graphically, the message "My number is 3" will be depicted by a green box above number 3 and red crosses above $0,1,2,4$ and 5 :

My number is 3 .

$\begin{array}{llllll}\times & \times & \times & & \times & \times \\ 0 & 1 & 2 & 3 & 4 & 5\end{array}$

\section{Decision of player E}


Player E either sees the message sent by player S or sees the note "Player S has not sent you a message." if player S has decided not to send a message.

Then, player E must enter his or her guess about the actual number of player S. Here, every number can be entered in 0.5-intervals $(0,0.5,1,1.5,2,2.5,3,3.5,4,4.5,5)$.

\section{Payoff}

The payment is determined by the following rules: The higher the guess of player E, the higher the payment of player S. And the closer the guess of player $\mathrm{E}$ is to the true number of player $\mathrm{S}$, the higher the payment of player $\mathrm{E}$.

Hereafter, the mechanism which determines the payment is explained in detail.

In each round you can earn between 0 and 100 probability points (PP). The more probability points you earn, the higher the probability that you win the subsequent lottery:

\begin{tabular}{|c|c|}
\hline Probability & Payoff \\
\hline PP\% & 8 Euro \\
\hline$(100-P P) \%$ & 1 Euro \\
\hline
\end{tabular}

If you gain 0 probability points you receive with certainty (with 100\%) 1 Euro. If you gain 100 probability points you receive with certainty (with 100\%) 8 Euro. If you gain e.g. 70 probability points, you receive, with the probability of $70 \%, 8$ Euro and, with the probability of $30 \% 1$ Euro. The more probability points you gain, the more probable it is that you receive 8 Euro instead of 1 Euro.

Thus, you should try to gain as many probability points as possible.

The amount of your probability points in one round depends on both the number of player S and the guess of player E. The payoff table, which you can find at your spot, makes this clear. If player $\mathrm{S}$ e.g. receives the number 3 and player $\mathrm{E}$ guesses number 4.5, player E gains 79 probability points and player S 96 probability points. But, if player E guesses that the number of player $\mathrm{S}$ is 1, then player $\mathrm{E}$ gains 69 probability points and player S only 19 probability points.

Only one of the 15 rounds is chosen randomly and then is actually relevant to the payoff. Your probability points in this round determine the lottery which is played by the 
computer at the end of the experiment. Since you do not know, which of the 15 rounds is relevant to the payoff you should think about your decisions in each round.

\section{Summary}

- Player $\mathrm{S}$ receives a random number that is unknown to player E.

- Player S decides whether or not to send a message to player E regarding the number. The message must contain the number of player $\mathrm{S}$.

- What the message contains is determined by player S.

- Player E must guess the number of player S.

- The higher player E guesses the number of player S, the higher the chances of profits for player S.

- The more accurate the guess of player $\mathrm{E}$ for the number is, the higher the chances of profits for player E.

\section{F.3 Payoff tables}

Table 8 Payoffs of Player E

\begin{tabular}{|c|c|c|c|c|c|c|c|c|c|c|c|c|}
\hline & \multicolumn{11}{|c|}{ Guess of Player E } \\
\hline & & $\mathbf{0}$ & 0.5 & 1 & 1.5 & 2 & 2.5 & $\mathbf{3}$ & 3.5 & 4 & 4.5 & 5 \\
\hline \multirow{6}{*}{ Number of Player S } & $\mathbf{0}$ & 100 & 96 & 88 & 79 & 69 & 58 & 46 & 32 & 19 & 4 & 0 \\
\hline & 1 & 88 & 96 & 100 & 96 & 88 & 79 & 69 & 58 & 46 & 32 & 19 \\
\hline & 2 & 69 & 79 & 88 & 96 & 100 & 96 & 88 & 79 & 69 & 58 & 46 \\
\hline & 3 & 46 & 58 & 69 & 79 & 88 & 96 & 100 & 96 & 88 & 79 & 69 \\
\hline & 4 & 19 & 32 & 46 & 58 & 69 & 79 & 88 & 96 & 100 & 96 & 88 \\
\hline & 5 & 0 & 4 & 19 & 32 & 46 & 58 & 69 & 79 & 88 & 96 & 100 \\
\hline
\end{tabular}

Table 9 Payoffs of Player S

\begin{tabular}{|c|c|c|c|c|c|c|c|c|c|c|c|c|}
\cline { 3 - 15 } \multicolumn{1}{c|}{} & \multicolumn{10}{c|}{ Guess of Player } \\
\cline { 2 - 14 } & $\mathbf{0}$ & $\mathbf{0 . 5}$ & $\mathbf{1}$ & $\mathbf{1 . 5}$ & $\mathbf{2}$ & $\mathbf{2 . 5}$ & $\mathbf{3}$ & $\mathbf{3 . 5}$ & $\mathbf{4}$ & $\mathbf{4 . 5}$ & $\mathbf{5}$ \\
\hline \multirow{4}{*}{ Number of Player S } & $\mathbf{0}$ & 0 & 4 & 19 & 32 & 46 & 58 & 69 & 79 & 88 & 96 & 100 \\
\cline { 2 - 15 } & $\mathbf{1}$ & 0 & 4 & 19 & 32 & 46 & 58 & 69 & 79 & 88 & 96 & 100 \\
\cline { 2 - 15 } & $\mathbf{2}$ & 0 & 4 & 19 & 32 & 46 & 58 & 69 & 79 & 88 & 96 & 100 \\
\cline { 2 - 14 } & $\mathbf{3}$ & 0 & 4 & 19 & 32 & 46 & 58 & 69 & 79 & 88 & 96 & 100 \\
\cline { 2 - 13 } & $\mathbf{4}$ & 0 & 4 & 19 & 32 & 46 & 58 & 69 & 79 & 88 & 96 & 100 \\
\cline { 2 - 12 } & $\mathbf{5}$ & 0 & 4 & 19 & 32 & 46 & 58 & 69 & 79 & 88 & 96 & 100 \\
\hline
\end{tabular}

